\title{
El complejo papel de la violencia para sustentar o desafiar la autoridad policial en el Territorio Nacional de La Pampa, 1884-1930
}

Le rôle complexe de la violence pour appuyer ou défier l'autorité policière dans le Territoire National de La Pampa, 1884-1930

The complex role of violence to sustain or challenge the police authority in the National Territory of La Pampa, 1884-1930

\section{Melisa Fernández Marrón}

\section{OpenEdition}

Journals

Edición electrónica

URL: http://journals.openedition.org/rhj/2861

DOI: 10.4000/rhj.2861

ISSN: 0719-4153

Editor

ACTO Editores Ltda

Referencia electrónica

Melisa Fernández Marrón, « El complejo papel de la violencia para sustentar o desafiar la autoridad policial en el Territorio Nacional de La Pampa, 1884-1930 », Revista Historia y Justicia [En línea], 13| 2019, Publicado el 19 noviembre 2019, consultado el 26 mayo 2020. URL : http:// journals.openedition.org/rhj/2861; DOI : https://doi.org/10.4000/rhj.2861

Este documento fue generado automáticamente el 26 mayo 2020

Revista Historia y Justicia 


\section{El complejo papel de la violencia para sustentar o desafiar la autoridad policial en el Territorio Nacional de La Pampa, 1884-1930}

Le rôle complexe de la violence pour appuyer ou défier l'autorité policière dans le Territoire National de La Pampa, 1884-1930

The complex role of violence to sustain or challenge the police authority in the

National Territory of La Pampa, 1884-1930

Melisa Fernández Marrón

\section{NOTA DEL EDITOR}

Recibido: 21 de mayo de 2019 / Aceptado: 07 de octubre de 2019

\section{Introducción}

1 A fines del siglo XIX y durante la primera mitad del siglo XX, la violencia en el espacio público y privado, especialmente asociada al mundo masculino, fue un aspecto cotidiano tanto en la campaña como en los incipientes centros urbanos del Territorio Nacional de La Pampa ${ }^{1}$. Para construir una sociedad cuyos actores se convencieran de que el único espacio para dirimir los conflictos interpersonales era el Estado, había que terminar con los enfrentamientos que se ejercían a título individual. Sin embargo, en otros estudios sobre el perfil de los funcionarios policiales y la forma de desempeñar sus funciones se ha evidenciado hasta qué punto el Estado debió apoyarse en la sociedad territoriana para construir un aparato burocrático ${ }^{2}$. Con ese cuerpo de funcionarios, resultaba difícil imponer un orden distinto del que los pobladores 
consideraban legítimo, máxime cuando éste se enfrentaba a intereses de las redes locales y a prácticas reconocidas como válidas desde tiempo atrás ${ }^{3}$, como el uso de las armas. De este modo, la vigencia de la costumbre se transformó en un objeto de disputa social.

2 El uso generalizado de las armas enfrentó a los agentes de policía a sucesos que eran tan corrientes como incontrolables. La confusión generada por los cuerpos que se chocaban y se injuriaban ante la menor afrenta al honor y a las reglas de sociabilidad devenía en duelos de cuchillo y poncho. Así, el monopolio estatal de la violencia legítima era desafiado en permanencia. De manera tal que, difícilmente se cumplía con la regulación pública de la violencia privada. Como advierten algunos estudios, en ninguna parte la policía detenta el monopolio del uso reglado de la violencia, en el sentido estricto del término ${ }^{4}$. La coacción desde el Estado depende para ser eficaz de un consenso de valores o del consentimiento popular ${ }^{5}$.

3 Las reglamentaciones que restringían el uso de armas en manos de particulares condenaban las justas o pendencias y permitían la injerencia del poder policial y judicial en la vida privada. En 1886, el Reglamento de Policía Urbana y Rural prohibió, en el artículo $n^{\circ} 13$, "cargar o usar puñal, cuchillo, daga o arma de fuego dentro del radio de la ciudad". Unos años más tarde, en 1894, el Código Rural para los Territorios Nacionales contradecía esta normativa al establecer que la policía no podía impedir el derecho de llevar armas (artículo 253)7. Pero sí penalizaba su ostentación con una multa de diez pesos, y de cincuenta pesos por sacarla con el fin de amenazar. Avanzada la década de los veinte, la aplicación del Código Penal reformado (y, con él, las concepciones sobre lo que se entendía por delito) supuso la represión del abuso de armas. El artículo 104 establecía de uno a tres años de prisión para el que disparara contra una persona sin herirla y, a medida que disminuía la gravedad, la pena oscilaba de quince días a seis meses de cárcel aun cuando la agresión no causase daño ${ }^{8}$.

4 En la práctica, la convivencia de estos marcos legales comprometió la capacidad pacificadora estatal. Pero la poca eficacia de las normas no se traducía en la inexistencia de reglas en la sociedad. Por el contrario, ciertas reglas se negociaban en la cotidianeidad, donde la población reproducía códigos no escritos para mitigar y, a veces, burlar de manera abierta la injerencia estatal ${ }^{9}$.

5 En la nueva ordenación del espacio territorial pampeano, crear efecto de obediencia consentida entre quienes habitaban esas tierras no fue sencillo, si bien el mundo rural no vivía en la ilegalidad y el desorden, aunque rehuyera los controles de los aparatos estatales. Cuando el Estado afrontó la tarea de desplegar su acción policial en ese medio, se enfrentó a una sociedad recientemente creada por sujetos arribados de otros espacios geográficos, regidos por normas distintas y acostumbrados a resolver sus conflictos, en gran medida, al margen de las esferas estatales.

6 En efecto, aún cuando el Estado ejerció el control desarrollando una práctica judicial y policial, sería incorrecto imaginar que desaparecieron antiguas expresiones informales de la vieja infrajusticia -como la venganza, los duelos o los casos de vindicta colectiva y las muchas maneras de negociación- hasta entrada la década de los veinte ${ }^{10}$. A nivel de las prácticas, estas estructuras formales e informales de violencia penetraron en el Estado y desdibujaron las líneas que las diferenciaban.

7 En la década de 1980, los análisis sobre la criminalización de los paisanos en Argentina, expusieron la violencia machista y la debilidad del Estado para desmontarla ${ }^{11}$. Estudios 
posteriores para la campaña bonaerense han advertido cómo el Estado, en su intención de modelar una sociedad en vías de organización, se propone corregir las costumbres arraigadas y, para esta tarea, piensa en la colaboración de los vecinos ${ }^{12}$. Aunque muchos de estos estudios se enfocan en la reconstrucción del control social, la criminalidad y la formación estatal para diferentes espacios de la campaña bonaerense y la urbe porteña ${ }^{13}$, sólo recientemente se ha empezado a mirar con más detalle la dimensión interpersonal de la violencia en otros espacios, como los Territorios Nacionales ${ }^{14}$.

Este artículo analiza la articulación entre la figura policial en tanto representante de un Estado regulador de la violencia, y el uso efectivo de la violencia en las prácticas sociales. El trabajo sigue la trayectoria de la policía desde su creación en 1884 hasta los años treinta del nuevo siglo en torno a las prácticas y usos de las armas en el territorio. Tal elección busca aprehender la coexistencia de antiguas expresiones informales de la infrajusticia en relación a la configuración de la policía como institución encargada de detentar y aplicar los recursos de la fuerza. El cierre propuesto converge con una evolución de los delitos contra las personas que estaría reflejando la capacidad de un Estado cada vez más burocratizado para ejercer un control social efectivo. A tono con la búsqueda de profesionalización policial, los años veinte y treinta del siglo XX, pueden ser concebidos como un tiempo de crisis y de refundación institucionales, de rupturas y continuidades en la fuerza pública; donde modernización y tradición se mixturaban mucho más que reemplazarse o adversarse.

Poniendo en vínculo una serie diversa de fuentes, las secciones de este estudio procuran echar luz sobre cómo se atribuye la violencia ${ }^{15}$. En el apartado que abre el texto se examina el perfil de los usuarios de las armas. Se realizó una muestra cuantitativa de los expedientes de la Justicia Letrada Nacional, del período 1885 a 1930, que la justicia remitió al Archivo Histórico Provincial de La Pampa ${ }^{16}$. El tratamiento de estos datos permitió tener una visión global de las diversas causas sustanciadas.

10 El expediente judicial aporta una riqueza insustituible para conocer a los participantes de los embates armados. Entre sus muchas potencialidades, se usaron los expedientes para develar detalles de las prácticas sociales violentas (los lugares de enfrentamiento, las temporalidades y las armas utilizadas) y conocer la compleja interlocución entre los diferentes actores. No obstante, se advierte que el lenguaje legal y la intervención de los actores judiciales median y traducen las voces de los implicados.

11 Tomando nota de esa advertencia, de los novecientos treinta y dos expedientes catalogados en el archivo se confeccionó un universo de estudio de cien causas judicializadas. La delimitación de un corpus de estas características presupuso recortar en aquellas causas que permitieran acercarnos "al sistema de valores a través de la normativa, de las causas que originaban las querellas; así como desde la lectura de las exposiciones del caso por parte de las víctimas, de las declaraciones de los testigos, de los acusados y del resultado al que se arriba en las sentencias" ${ }^{17}$. De una serie de cuestiones metodológicas vinculadas a los desafíos que presentan las fuentes judiciales, es importante señalar que resulta difícil estimar el grado de representatividad de los expedientes ${ }^{18}$. Más allá de cada caso particular, expresa Alejandra Fernández, se pueden descubrir ciertos tópicos y afirmaciones recurrentes que remiten a lo que la sociedad consideraba correcto y ofensivo, honorable o deshonroso ${ }^{19}$.

12 En esta línea y en relación con la posibilidad que ofrecen los expedientes, la metodología utilizada se inscribe en la perspectiva desarrollada por otros estudios que han buceado en la criminalidad desde la historia social de la justicia. Se trata de un 
acercamiento que ha privilegiado los archivos judiciales como una herramienta fundamental para reconstruir los conflictos sociales, la institución judicial, sus actores, sus ideas, su formación, sus modos de intervención y los “arreglos" locales. Una opción metodológica que, a la vez, ha planteado las limitaciones con las que tropieza esta fuente para argumentar cuantitativamente ${ }^{20}$. En el segundo apartado se abordan las representaciones y los sentidos otorgados a la violencia en la prensa comercial y en fuentes oficiales. Junto a la indagación de los códigos penal y rural vigentes en el período, se busca conocer los criterios con los que se juzgaba la portación y circulación de las armas. La empresa periodística era un espacio vital que reflejó las disidencias, las diferentes perspectivas y las quejas de numerosos interlocutores. Como han observado los estudios sobre la prensa, quienes tenían mayor habilidad y posibilidad para iniciar controversias eran los periodistas y dueños de periódicos, quienes con sus notas y editoriales colaboraron en instalar y fortalecer imágenes de desorden y marginalidad respecto de los centros de poder.

\section{Los Moreira}

El 13 de mayo de 1912, se informó a la comisaría del séptimo departamento de un enfrentamiento en el andén de la estación del ferrocarril Oeste, en el pueblo de Victorica. El personal de policía dio inicio al acta de lo denunciado por el capataz del galpón, Ángel Faidutti. Encontrándose junto al jefe de dicha estación y al telegrafista, observaron cómo, después de surgir un disgusto entre Juan Castro y "Ballesteros", comenzaron a reñir por bromas, luego de intercambiar insultos. Castro sacó un cuchillo de cabo blanco de veintidós centímetros de hoja que llevaba entre sus ropas y dio inicio a un cruce de golpes en el suelo. Al calor de la riña, "Ballesteros" buscó en la sala de faroles un cabo de escoba con el que se abalanzó sobre Castro y le asestó tres golpes en el cuerpo y la cabeza. El jefe de la estación intervino y los separó.

14 Al ser interrogado por las autoridades, Castro, peón de cuadrilla permanente del ferrocarril, adujo que su contrincante, con tono amenazador, le había susurrado "mira qué Moreira para que traiga cuchillo... bueno para quitárselo y a trompadas" ${ }^{21}$. Y, aunque su intención no era pelearse, confesó que tuvo que responder haciendo ostentación del arma. Ante el jurado, quedó demostrado que el damnificado había guardado una actitud prudente con respecto al victimario, y no se lo condenó por agresión a mano armada. Por su parte, el diagnóstico médico-legal demostró que la herida sanaría en cinco días y no tendría consecuencias.

15 En la averiguación realizada por el Juzgado Letrado Nacional del Crimen, se conoció que "Ballesteros" era el sobrenombre de Francisco Pizarro. Había nacido en la Argentina, vivía en la zona accidentalmente y contaba con veintiséis años de edad cuando fue aprehendido por la policía. Era casado y alfabeto; además, trabajaba como cambista en la estación. En el interrogatorio, el acusado sostuvo que la víctima lo había amenazado con su cuchillo y que él se había defendido con un cabo de escoba, actuando en legítima defensa. Con esta información, siete días después se citó a los incomunicados alojados en la cárcel capitalina para ratificar sus declaraciones y nombrar un defensor. "Ballesteros" fue sentenciado a seis meses de prisión, purgados por el tiempo que había estado detenido. Al violentarse, había quebrantado la ley y causado lesiones leves a la víctima. 
16 El caso de "Ballesteros" vs. Castro no fue muy distinto de aquellos que se desarrollaron, con desenlace de gravedad desigual, tanto en la ciudad como en la campaña del territorio; más bien, fue característico de la violencia que se vivía en esos espacios. También, refleja la naturalización de las prácticas de la fuerza, espaciales y corporales, que organizaron relaciones en la sociedad y construyeron subjetividades. En esa dinámica social en la que algunos individuos resolvían sus conflictos optando por la violencia, ¿cuál era su perfil? y ¿cuáles, los números de esa forma de "criminalidad"?

Según el proceso judicial que se abrió en contra de Ballesteros, se puede observar que los usuarios de las armas fueron frecuentemente nombrados (por ellos mismos y por la prensa también) como Moreira. Esta representación nos remite al personaje que vivió a fines del siglo XIX y fue consagrado en papel por Eduardo Gutiérrez. Juan Moreira resucitó en cada uno de ellos ${ }^{22}$. No para robar y dar a los más pobres, no para formar parte del Estado que luego lo asesina: aparece para sentenciar, para hacer valer su poder de dar muerte o vida. Está presente para arrebatar palabras y convertirlas en puñaladas. Así, los elementos que utilizaron periodistas y policías para describir a la sociedad pampeana se remontan a la vieja tradición literaria decimonónica ${ }^{23}$. No se trataba, pues, del malevaje criollo representado en la figura del gaucho ni tampoco del compadrito arrabalero porteño. Salvo raras excepciones, el imaginario apeló a bandidos o pistoleros.

18 Si se realiza una operación metodológica de discriminación y agrupamiento de los emisarios y destinatarios de la violencia, es posible percibir que se ejerció entre hombres jóvenes que se desempeñaban como jornaleros (en hornos de ladrillos, en los vagones del ferrocarril, carreros, puesteros, bolseros...), comerciantes, chacareros, presidentes de romerías, vendedores ambulantes, cocheros, médicos, periodistas, entre tantos otros oficios y profesiones.

19 Cabe indicar que esta diversidad de indicadores socio-ocupacionales estaba en correspondencia con la estructura productiva del territorio. En la encrucijada de los siglos, el desarrollo de las actividades económicas y las nuevas formas de ocupar el espacio impactaron en la composición y distribución de los pobladores y en la construcción de infraestructura, en particular el transporte y el desarrollo de industrias locales. Con el advenimiento del siglo XX, la agricultura y el mejoramiento del ganado vacuno en la franja este del territorio comenzó a desplazar la producción lanar hacia el oeste. En tal sentido, distribuidos de forma heterogénea, los recursos naturales más aptos en La Pampa se concentraron en la primera de estas franjas del territorio, que reunía las condiciones agronómicas que se adaptaban mejor a las exigencias de los bienes solicitados por la demanda internacional en plena expansión. Este fue el escenario exclusivo donde menos de una tercera parte del conjunto territorial concentró la población, los granos y los ganados ${ }^{24}$. Este apunte confirma que La Pampa fue un espacio que tuvo diferentes niveles de articulación socioeconómica, política, social e institucional.

Del total de los casos, se desprende que el infractor y la víctima (por lo general, también varones) que comenzaban a discutir, pelear o agredirse brutalmente eran, en su mayoría, vecinos, compadres, compañeros de trabajo que poseían un lazo de amistad o un trato efímero previo (que variaba según el tiempo transcurrido en un trabajo y el que tardaban en volver a desplazarse hacia otra oportunidad laboral). En su mayoría, se observa un alto porcentaje de analfabetismo: aunque algunos firman, no saben leer y escribir. 
21 En general, no se evidencian en los expedientes trayectorias o carreras criminales detrás de estos episodios. Como es conocido, las estadísticas policiales son fragmentarias, pues ocultan la cifra "negra" de los casos no denunciados y no existen registros de largo aliento para inferir algunas tendencias, además de las preconcepciones institucionales con que cargan y seleccionan transgresiones ${ }^{25}$. Teniendo en cuenta estas restricciones y reparos, se observa, según los datos policiales, que las cifras de las ilegalidades relacionadas con las armas fluctuaron en el tiempo y se mantuvieron en alza aun avanzados los años veinte. En 1891, las causas por el uso de armas, con un total de 109, se ubicaban detrás de los casos por ebriedad y escándalos. En 1911, los detenidos por atentar contra las personas llegaban a superar los delitos contra la propiedad, con un número de 297 procesados. Para 1925, el registro de la Jefatura informó 253 casos (desagregados en 48 homicidios, 169 lesiones y 36 abusos de armas). En la década de 1930, los hechos continuarán manteniéndose casi en el mismo nivel, con 211 procesados (24 abusos de armas, 134 lesiones, 32 agresiones y 21 homicidios) $)^{26}$.

Las causas judicializadas permiten recabar información sobre la cantidad de delitos según el tipo de causa y su distribución geográfica. Una lectura del primer gráfico sugiere el elevado porcentaje de delitos por lesiones corporales (en sus diferentes formas) en relación con los casos por homicidio ${ }^{27}$. También se puede mencionar que, al alejarnos del principio del siglo XX, decrece el nivel de violencia utilizado en las contiendas interpersonales. En gran medida, los conflictos suelen ser lesiones y agresiones, pero, cada vez en menor proporción, homicidios.

Gráfico 1. Valores por tipo de causa en delitos contra las personas en La Pampa (1895-1930)28

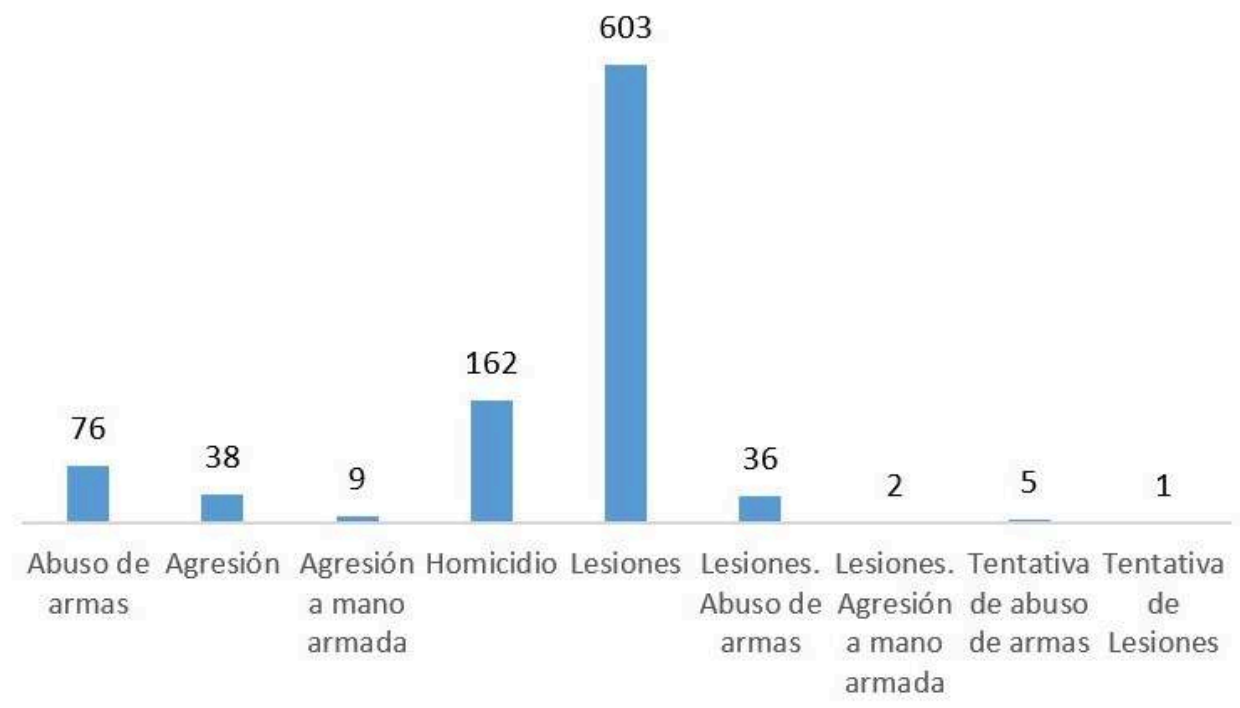

Fuente: elaboración propia a partir de 932 expedientes de la Justicia Letrada Nacional Secretaría en lo Penal, 1885-1907, de la Justicia Letrada Nacional del Crimen, 1907-1921 y Justicia Letrada Nacional del Fuero Penal Nº 1, 1921-1951.

Esta evolución en los delitos contra las personas se registrará a su vez si los comparamos con otro tipo de infracción. Como ha planteado Diez, a partir de 1905, las causas por presuntos delitos contra la propiedad comenzarán a superar a los que 
atentan contra las personas ${ }^{29}$. Aun así, a lo largo del período, la tendencia en los delitos contra las personas se sostendrá marcadamente constante.

Gráfico 2. Causas registradas contra las personas por decenios en La Pampa (1885-1930)

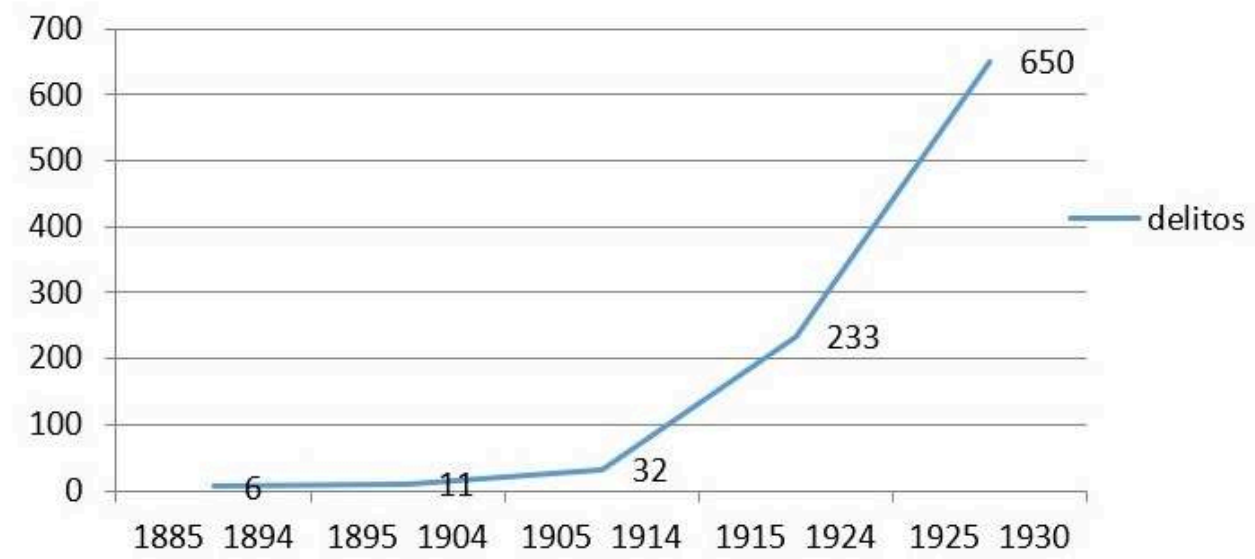

Fuente: elaboración propia a partir de 932 expedientes de la Justicia Letrada Nacional Secretaría en lo Penal, 1885-1907, de la Justicia Letrada Nacional del Crimen, 1907-1921 y Justicia Letrada Nacional del Fuero Penal N¹, 1921-1951.

¿Sugieren estos números un alto nivel de criminalidad?, ¿a qué se puede atribuir el crecimiento desigual pero sostenido del número de denuncias? En coincidencia con lo planteado en algunas investigaciones, la información de los casos registrados no es indicativa de variaciones en la criminalidad, sino de la capacidad del Estado para ejercer un control social efectivo ${ }^{30}$. En La Pampa, es probable que esta variación obedezca en parte a problemas de subregistro o mal registro de las denuncias. Sin descuidar este aspecto metodológico, se podría inferir que el incremento en el número no solo estuvo dado por el aumento real de delitos en proporción con el fuerte crecimiento de la población sino también porque, avanzados los años veinte, estas variaciones iban de la mano de una mejora en el control y la judicialización. En efecto, el crecimiento demográfico a lo largo del período acompañará la curva ascendente de causas registradas contra las personas, y por ende relativiza el aumento de casos (la población ascendía, en 1895, a 25.914; en 1914, a 101.338; en 1920, a 126.928; y, en 1930, pasó a 169.526 habitantes) ${ }^{31}$.

25 Al mismo tiempo, durante esa etapa, la institución comenzó a preocuparse por profesionalizar a los policías y sus prácticas. Con reformas aisladas y sin un impacto general, se buscó ordenar y (re)organizar una estructura institucional basada en la improvisación y la informalidad. Entre 1920 y 1930, se advierte la existencia de un período de transición caracterizado por la exigencia de una moralidad y racionalidad en la institución policial. Distintos intentos de reforma buscaron, por una parte, eliminar la arbitrariedad de los canales de acceso e instaurar un reclutamiento y entrenamiento formales; por otra parte, establecer un cuerpo de funcionarios estable y competente a partir de la creación de la carrera policial. Parte de este proceso se planteaba a través de la mejora en las condiciones laborales (aumento salarial y un 
acceso más fluido en el trámite de jubilación). Es probable que, en este contexto, los incidentes comenzaran a ser denunciados con mayor frecuencia en las comisarías, lo que hace suponer que se esté, principalmente desde esos años, ante un aparato judicial y policial más eficaz en la recolección de las denuncias, pero no por ello en la resolución de los conflictos.

En forma adicional, se presenta otro dato: los atentados se registraban en mayor número en los grandes poblados de la franja este del territorio. Como rasgo significativo, se puede señalar que sí para 1895 el 90,8 \% de la población residía en la campaña, para 1935 se evidencia una marcada tendencia a un mayor poblamiento en aquellas áreas en vías de urbanización $(40,6 \%)^{32}$. En el caso de la capital y un par de municipios, comenzaron a percibirse indicios de una transformación en la planta urbana. Los centros con mayor desarrollo aumentaron casi al doble su población. El resultado fue una sociedad que crecía con ritmos desiguales.

De acuerdo con estos datos, ¿cuáles eran las zonas donde mayor impacto tenían estos litigios? Los expedientes judiciales permiten constatar algunas cuestiones sobre la distribución geográfica de los delitos. Por un lado, el mayor número de delitos perpetrados en los centros urbanos (departamentos 1, 2, 3 y 7) 73 $^{33}$, comparado con la campaña, estaría mostrando la elevada movilidad geográfica y ocupacional característica de este espacio (el desplazamiento de los trabajadores del campo a la ciudad y viceversa). Antes que presumir que las ciudades eran más violentas que la campaña, se puede considerar que las diferencias entre zonas provienen, sobre todo, del desigual grado de institucionalización de la relación de la sociedad con la policía y de las prácticas sociales efectivas frente al sistema policial y a la proximidad de asiento del tribunal letrado y también a la mayor densidad demográfica. En La Pampa, donde las comisarías y destacamentos se difuminaban en el horizonte, la cercanía al personal policial era más inmediata en los centros urbanos, donde se podía denunciar o presentarse en una comisaría como víctima de un disturbio ${ }^{34}$. En cambio, hasta que algún pariente, vecino o el mismo damnificado llegaba a la repartición aledaña desde los campos y estancias, la demora era, tal vez, de uno o dos días.

Las causas se iniciaban por diferentes vías: cuando se presentaba a denunciar el infractor, la víctima, un testigo o el mismo oficial elaboraba el parte en la oficina. El policía ocupaba el lugar de autoridad una vez que las armas ya se habían disparado porque, en el proceso de enjuiciamiento contra el acusado, era importante el papel que desempeñaba la denuncia de lo ocurrido para evitar la sospecha de haber excedido la defensa propia. Era precisamente esa iniciativa lo que le permitía al Moreira reconocer al representante del Estado en el instante que la denuncia exponía lo acontecido. Recurrir a la denuncia apelando legítima defensa fue una estrategia de los involucrados para resolver el problema con la ley.

Una expresión de este recurso emerge del siguiente caso. A mediados de la primera década del novecientos, un puestero del establecimiento "Los Molinos", llamado Álvarez, denunció que un tal Aguirre, echando mano al cuchillo, lo había herido por la espalda. En una chacra, con algunos testigos que luego participarían del sumario, Álvarez y Aguirre se trenzaron en una pelea. Sin estar ebrios, discutían por una mujer. A juicio rápido, se podría decir que el condenado de esta historia fue el heridor. Sin embargo, en esta causa por lesiones subyacía la concepción jurídica imperante sobre la legítima defensa. La acusación del fiscal introducía la noción del ocultamiento: "si al herir o matar uno da aviso de lo ocurrido a la autoridad más inmediata, queda librado 
de sospecha". De lo contrario, si no se cumplía con esta obligación, "se presumiría que ha habido exceso en los límites de la defensa" ${ }^{35}$. Dado que la mayoría de los imputados trataban, con sus justificaciones, de evadir la responsabilidad penal alegando legítima defensa o de mitigar su rigor sosteniendo la provocación, eso no siempre era suficiente atenuante como para no ser procesado ${ }^{36}$.

30 Atacado de imprevisto por la espalda, Álvarez agredió a su adversario pegándole con su puñal y ocasionándole tres lesiones (en la cara, cabeza y mano). Su rival, por el contrario, no podía argumentar legítima defensa. "Irritado por los celos y falto de coraje”, atacó a su enemigo por la espalda, traicionándolo. Según la sentencia, el primero se excedió en la defensa porque el primer golpe ya intimidó a su contrario, que quedó asustado sin resolución de ataque con el revólver que portaba. Acto seguido pegó tres hachazos. "Hubo exceso, se pasaron los límites de legítima defensa. La franca exposición del segundo [Aguirre] hace creíble su afirmación de que en el primer momento de la lucha perdió su cuchillo y que sólo después de ella se acordó de su revólver" ${ }^{37}$. Definitivamente, dictaminaba el juez, se había cometido delito por lesiones con "el agravante de deformación permanente en el rostro". La víctima inicial de la causa terminaría siendo condenado a tres años de penitenciaría, mientras Aguirre recibiría solo dos de encierro. Medio año después del enfrentamiento, Aguirre pagó su condena en prisión preventiva, mientras Álvarez, vencida su pena, continuaría preso un tiempo más.

31 Como sugiere esta causa, y otras más, la mayoría de los enfrentamientos se desencadenaban cuando se creía agraviado o cuestionado el honor y el poder masculinos: rivalidades, malos entendidos, venganzas, ofensas de palabras y desafíos explícitos, demostraciones de valentía o de fuerza motivaban las contiendas. Las palabras, los gestos y los golpes propinados respondían a la velocidad de las injurias cometidas. Por ende, los hombres se veían compelidos a responder públicamente un agravio si querían conservar el respeto social (y político, en algunos casos). No era una opción, sino una obligación ${ }^{38}$. Desde la concepción tradicional de ser varón, estas expresiones constituyeron un tipo de violencia que era frecuente en los tradicionales espacios de sociabilidad ${ }^{39}$.

32 La temporalidad de los acontecimientos armados da cuenta de ello. Luego de finalizado el trabajo, en especial el rural, se regresaba a la casa o se dirigía a algún lugar de recreación. Las pendencias tendían a desencadenarse, aproximadamente, después de las 5 p.m. y durante las horas de la noche ${ }^{40}$. A la luz de la evidencia, el terreno donde podían desarrollarse las encerronas diarias de las armas eran boliches, fondas y prostíbulos. A estos espacios donde se acostumbraba a socializar, se sumaba como posible escenario la vivienda personal de la víctima o del victimario. En el marco de cada riña, aquel que se encontraba en estado de ebriedad tenía mayores posibilidades de hallarse envuelto en alguna trifulca.

33 A los usuarios de las armas los unía la frecuentación de la misma casa de negocios donde beber, jugar, hablar, informarse de los hechos de último momento y los rumores de los alrededores. Los boliches eran el gran telón de fondo donde sucedían las pendencias con instrumentos cortantes. Se configuraban como el corazón del pueblo donde las ideas políticas, los romances, los celos y los arreglos personales se presentaban ante un grupo de concurrentes de lo más diverso. Peones agobiados después del día de cosecha, ebrios consuetudinarios, jefes políticos o comisarios, cada uno participaba de ese espacio de sociabilidad popular donde la distensión y el 
encuentro a menudo derivaban en grescas. Abiertos hasta medianoche, estos lugares de encuentro eran un foco de peleas que las autoridades debían a menudo obligar a cerrar. En estos pequeños y casi escondidos negocios confluían muchos parroquianos y se camuflaban elementos maleantes y pendencieros.

Una respuesta fue regular a quienes comerciaban los licores. Se "comprometía moral y reglamentariamente a los establecimientos a no vender bebidas a menores de 18 años, personal en servicio y a todo aquel que mostrara signos de ebriedad". El castigo al dueño del mostrador era igual al que recaía sobre el bebedor ${ }^{41}$. Porque era considerado "tan delincuente o más" el que fomentaba el alcohol como el que se embriagaba ${ }^{42}$. De hecho, no faltaban quienes en el socialismo local establecieron paralelos entre el efecto del alcohol y su incidencia en las peleas. Duramente, señalaban cómo día a día las crónicas policiales registraban un numeroso porcentaje de crímenes y atentados motivados por el estado de embriaguez de muchos hombres ${ }^{43}$.

Esto no era nuevo. Este tipo de denuncias no solamente constituía material de gran interés para la prensa gráfica comercial, además formaba parte de las campañas contra el consumo del alcohol. La inquietud que despertaban los aspectos morales de sus consumidores iba de la mano de la recurrencia con la que solicitaban como atenuante los efluvios del alcohol en los juicios por lesiones y disparos de $\operatorname{armas}^{44}$. Así, es frecuente leer en los expedientes judiciales: "embriagado hasta el extremo de perder la conciencia", "no recuerda nada, estaba muy ebrio"... frases que develan cómo la embriaguez alternaba rápidamente en escenas de lesiones y agresión a mano armada que podían derivar en delitos violentos. Para ser absorbidos de culpa y cargo, se apelaba al artículo 81 del Código Penal. Pero la misma letra de la ley sostenía que, para que la ebriedad fuese considerada eximente de responsabilidad, debía ser involuntaria ${ }^{45}$.

A juzgar por las causas estudiadas, individuos de diferentes sectores sociales portaban armas sin ninguna restricción, lo cual implica que la violencia individual era una hipótesis ampliamente compartida. La pólvora o la puñalada consumaban muchos conflictos, y cerraban cualquier posibilidad de disculpas o resolución por otra vía. Así, la gama de armas utilizadas por individuos del común fue de lo más diversa: revólveres, carabinas, palas, piedras, rebenques, cuchillos, palos de escobas, pesas de balanza, cadenas de hierro, entre otras. Parece claro que los obreros, jornaleros y peones acostumbraban a llevar un cuchillo como parte de sus herramientas de trabajo, y ciertamente lo utilizaban para defenderse o atacar. De este modo, el cuerpo quedaba siempre expuesto, y las armas eran una prolongación de su reputación, de su audacia, de su virilidad ${ }^{46}$. 
Figura 1. Armas usadas por agresor y agredido en contienda personal.

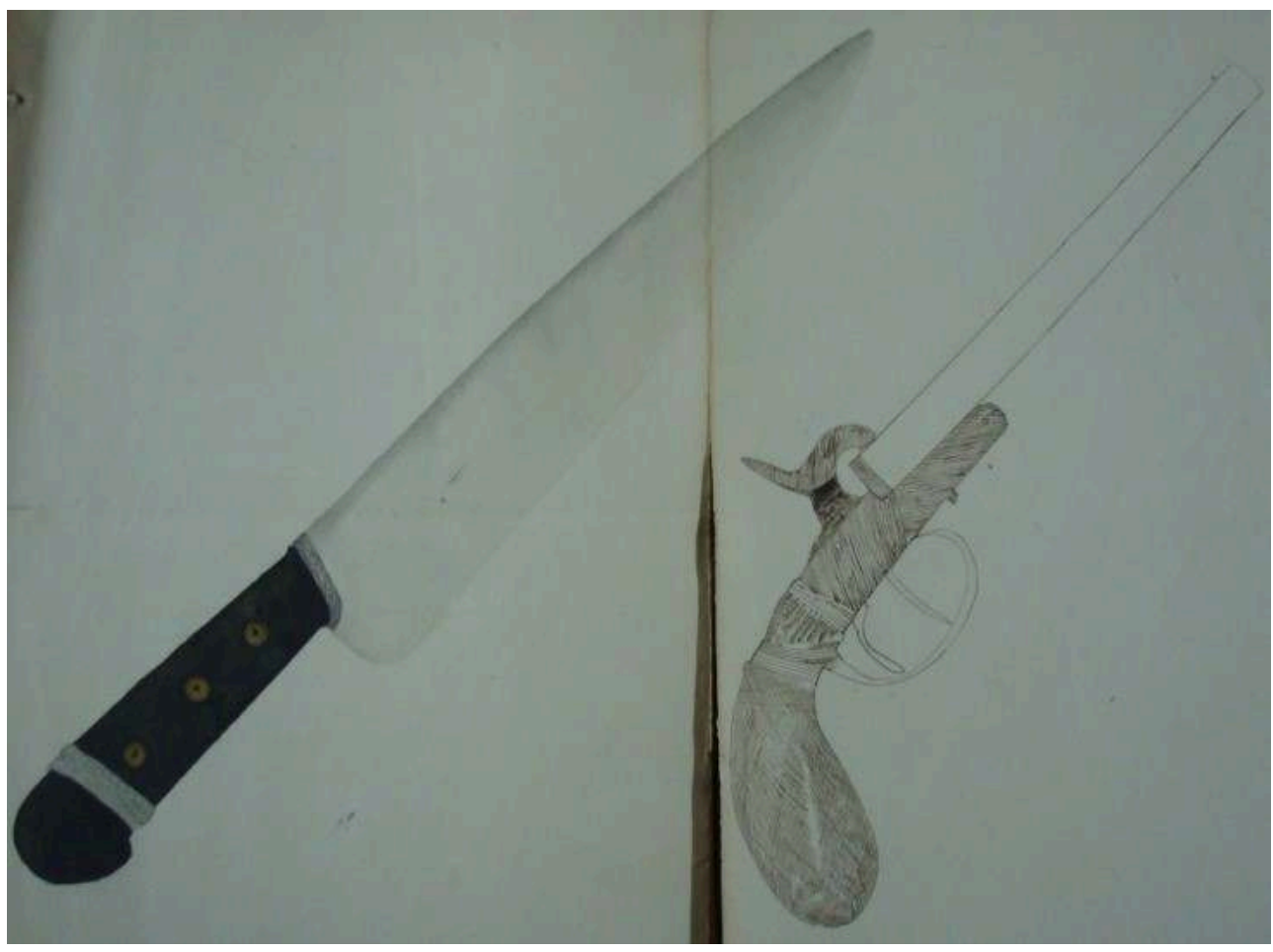

Fuente: AHPLP, JLNSP, C 1, E L-192, 5 de julio de 1885.

La circulación y el acceso a las armas de fuego comenzaron a registrarse a principios del siglo XX. Los incipientes comercios y almacenes de ramos generales buscaron satisfacer la demanda de una creciente y diversa población, ofreciendo toda clase de artículos. En las denominadas "armerías", las armas fueron objetos centrales de comercialización junto a la oferta de joyas, platería, relojería, máquinas de escribir e instrumentos musicales ${ }^{47}$. Los consumidores, en tanto, fueron interpelados a partir de anuncios publicados en los periodísticos o guías elaboradas por referentes del Territorio, entre otros. Al incorporar gustos vinculados a varios sectores de la sociedad, la publicidad de las armas ganó terreno. Al igual que lo que sucedía en otras zonas del país, se puede conjeturar que el mercado de las armas pampeano ofertaba artefactos de fuego a un costo accesible ${ }^{48}$. Como exhibía una propaganda de "Enrique Sturba", la gama de ofertas incluía revólveres, escopetas, pistolas, Winchester, balas, municiones y cartuchos.

Resulta notable que, derogada la Ley 4.189 con la reforma del Código Penal en 1921, en los casos analizados no se cuestionara por qué el acusado portaba una pistola o si tenía permiso para ello y, en consecuencia, que no se lo penara. Solo se decomisaba el arma como cuerpo del delito. Esto lleva a suponer que la sociedad continuaba armada, y que era fácil conseguir un arma de fuego. Ante este tipo de transgresión, tanto jueces como policías eran indulgentes con los sujetos armados, y la sanción por este tipo de delito era menor con respecto a otras modalidades de transgresión. A la larga, ello contribuyó a mantener este tipo de causas.

En síntesis, la continuidad de los casos de violencia por mano propia evidencia la debilidad del Estado para imponerse como única autoridad capaz de gestionar los conflictos interpersonales. Sin embargo, también habla de mecanismos internalizados de hombres jóvenes, solteros, con bajo nivel de alfabetización y, en su mayoría, provenientes de algún segmento ocupacional del campo, que no dudaron en hacer 
justicia, negociar y resistir. Como se ha expresado más arriba, para los varones, el uso de la fuerza parece haber sido un modo de reforzar el sentimiento de virilidad. Según Mauger, la fuerza es una dimensión inscripta en la virilidad y, por lo tanto, altamente valorada por los sectores populares ${ }^{49}$. En el marco del proceso modernizador y civilizatorio que hacía de la pacificación uno de sus centros, los sectores trabajadores de la llanura aun resistían la condena al uso cotidiano de las armas.

\section{Violencia sin fin}

En 1921, un artículo publicado en el diario La Autonomía de Santa Rosa se preguntaba si la criminalidad se había convertido en un hábito, subrayando que en la sociedad local el desprecio a la vida propia y a la de los semejantes eran moneda corriente. En los tiempos que corrían, discusiones acaloradas sin motivo alguno y "por causas del momento" mostraban un estado casi ajeno a la razón que se interponía entre los hombres.

Han soplado malos vientos y ha traído derroche de odio humano. El uso y abuso de las armas, de fuego especialmente, con sus consecuencias fatales. Hace falta la propaganda de la templanza entre los hombres. Y sobre el odio, la rebeldía y la efusión que arma el brazo homicida estaría un mundo nuevo de mejor moral y más nobles sentimientos. La humildad sería como debe ser en su idealidad, más buena ${ }^{50}$.

41 Tanto la prensa como los sectores con mayor arraigo local (maestros, "notables", comerciantes y propietarios de la zona) comenzaron a considerar estas formas de expresión un signo del carácter poco "civilizado" y falto de cultura de las clases subalternas. Ante este diagnóstico, se alertaba sobre el peligro a la "habituación" de los hechos armados que a "fuerza de repetirse llegan a la vulgaridad"

42 En sus dos volúmenes sobre el "proceso civilizatorio", Norbert Elias muestra que las formas de la violencia individual se modifican según la coacción esté o no institucionalizada. Para el autor, las sociedades europeas experimentaron una declinación de las agresiones como un proceso paralelo al creciente poder punitivo del Estado. Elias observaba, además, que en cada sociedad y en cada contexto histórico, los hechos violentos generan reacciones emocionales diferentes, como resultado de estructuras psíquicas de los individuos creadas por largos procesos de adaptación de los hábitos, las costumbres y las sensibilidades. Así, el cambio en las susceptibilidades impulsaba aspectos de lo que era "apropiado" y establecía juicios sobre lo que era o no ofensivo y vergonzoso ${ }^{52}$. Retomando esta idea, en este apartado se considerarán las representaciones y sentidos atribuidos a la violencia.

Los principales diarios capitalinos pampeanos manifestaron interés permanente en explicar la violencia que denunciaban. En efecto, La Autonomía sugería que "el desenfreno en las pasiones" junto con "la huida de la prudencia" daba paso en el hombre a un "sentimiento rebelde, inhumano y sanguinario" 53 . Era esa "naturaleza", que provenía de las bajas pasiones, del estado de acaloramiento o de irritación, la que se ponía en discusión a la hora de esclarecer las causas de las desgracias de sangre. En el fondo, el peligro radicaba en el desconocimiento, temperamento y genio del "otro". "Nadie puede conocer en cada uno las intenciones siniestras que en un momento quitan la vida a sus semejantes" ${ }^{44}$. para hablar de los transgresores del cambio de siglo en las ciudades portuarias 
cosmopolitas. Oleadas de inmigrantes jóvenes y solteros de diferentes nacionalidades, idiomas y religiones fueron descriptos por sus "antagonismos atávicos de raza que aún no han desaparecido a pesar del generoso ambiente de este país y la amplitud de La Pampa que los cobija" 55 . Esta realidad surcada por individuos "inadaptados" al ritmo del crecimiento territorial era retratada mediante un discurso pleno de reminiscencias del repertorio conceptual médico-legal de fines del siglo $\mathrm{XIX}^{56}$. De este modo, la caracterización de los usuarios de las armas estuvo atenta a las cadenas etiológicas que precedían la explosión de violencia en cuestión, y fueron definidos según ejes legales, morales y psicológicos. A diferencia del pistolero recreado por la cualidad performativa de su acción en las revistas y diarios porteños ${ }^{57}$, la pregunta que subyacía en la reconstrucción de las andanzas de los Moreira en la pampa seguía siendo "por qué" se delinque.

En la era de la prensa y de la modernización tecnológica, las publicaciones comenzaron a prestar atención a la persistencia de las prácticas de la violencia ${ }^{58}$. A fines del siglo XIX y apenas comenzado el siglo XX, los matutinos incorporaron una sección bajo el título de "Policiales" que enunciaba los actos delictivos y contravencionales de la región. Incluían, en su columna fija, relatos informativos breves sobre los acontecimientos. En las páginas había, además, artículos de mayor extensión que tenían como foco de interés los delitos contra la propiedad. Aparecían episodios, comentarios y acusaciones que captaban conductas puntuales de la vida en el interior de la campaña.

Entrada la década del veinte, los incidentes interpersonales reportados transformaron a la crónica roja en una noticia destacada. Si hasta entonces el parte policial relataba breves menciones sobre este tipo de casos delictivos, en el ciclo que se inicia en los años veinte se profundizaría la divulgación de los episodios armados. Durante esos años, la cobertura de casos como "un atentado a mano armada seguido de asesinatos o lesiones y heridas gravísimas de puñal o de bala contra particulares o funcionarios públicos en misión de mandatos u órdenes judiciales" era tres veces mayor que antes.

Los periodistas llegaban a la noticia por distintos informantes de manera casi inmediata. Hombres de confianza, testigos atónitos que hacían correr la voz, menores canillitas, todos aportaban al rojo del suceso. En muchas ocasiones, los niños interpretaron el papel de informantes. Irrumpían en la oficina con voz entrecortada anunciando el último incidente que demandaba la presencia policial. En distintas oportunidades, la prensa conocía los incidentes muchas horas antes que la jefatura ${ }^{59}$.

Por cada derramamiento de sangre cotidiano que se producía, La Autonomía, diario capitalino de tendencia radical y fuerte opositor de los gobiernos de turno, resaltaba el "asunto de andar a los tiros o balazos". Como consecuencia, el espacio concedido a la sección creció exponencialmente en esta época, producto de una operación política y, posiblemente, comercial. Con una estética diferente, sobresalían títulos de gran tamaño y epígrafes sensacionalistas. La enorme visibilidad de los títulos y subtítulos de tipo y cuerpos de letras distintos, que ocuparon una centralidad en la hoja, anticipaban lo que se leería en la nota. Su estructura no se basaba en el modelo genérico de la crónica policial. No se utilizó la figura del narrador-personaje, la transcripción de diálogos, los reportajes o la creación de un suspenso ${ }^{60}$. Tampoco el redactor apelaba a procedimientos ficcionales ni a la reconstrucción de la noticia a través de imágenes, ilustraciones o fotografías. Se buscó informar más que emocionar. Mientras la metrópolis porteña se entretenía y ampliaba sus percepciones del delito a través de los 
estímulos del cine, de la radio y de los periódicos, el repertorio local retrató escenas de la violencia campestre y urbana siguiendo un repertorio expresivo más tradicional ${ }^{61}$.

Volviendo a las preguntas planteadas por el periodismo, si la criminalidad se había convertido en un hábito, ¿cómo podían responder la sociedad y el Estado en un espacio que distaba de manifestarse apacible? A lo largo del tiempo, varios fueron los "peligros" que se manifestaban en esta llanura: delitos diversos, en especial el cuatrerismo, y más tarde, el temor a la expansión ácrata y a la movilización obrera. Un contexto hostil en el que la sociedad resolvía sus diferencias y rivalidades a través de la violencia.

Las elites políticas bregaron de maneras diversas para que las relaciones sociales cotidianas perdieran su filo más agresivo ${ }^{62}$. Pero inclusive los sectores que no participaban activamente de situaciones de este tipo, o que lo hacían de manera ocasional, conocían las reglas de juego y sabían cómo enfrentarlas. Si bien la represión fue uno de los métodos más frecuentemente usados por el Estado, también se pusieron en práctica otros de carácter simbólico y normativo. De modo que, a partir de 1920, se llevaron adelante una serie de procesos para regular el espectáculo de las agresiones y la violencia ${ }^{63}$.

51 Junto con la policía, otras instituciones convergieron en el desarrollo de la misión "civilizadora" estatal. Para transformar los hábitos y las costumbres, era necesario promover los símbolos unificadores de la cultura nacional, los mismos que estaban siendo promovidos en todas las provincias y territorios nacionales. Con ese fin, se establecieron en todos los pueblos escuelas nocturnas, talleres de arte, centros que ofrecían conferencias semanales y bibliotecas públicas. El paso por estos establecimientos se esperaba, induciría a un refinamiento de las conductas a través del contacto con una selección de mensajes culturales. En los años veinte, las huelgas obreras y de peones rurales activaron un discurso en el que el desorden social y moral se había extendido en el país. En esa coyuntura, mientras se sembraba un clima de alarma en la opinión pública, se apelaba a una defensa de la argentinidad amenazada por agentes foráneos e ideas maximalistas ${ }^{64}$. Esos discursos siguieron ocupando lugar en las páginas de la prensa y en la elite política y económica aun después de la finalización de esos conflictos. En el caso de los Territorios Nacionales, estos espacios serían percibidos por los sectores dirigentes como débilmente integrados al "alma nacional". De este modo, reforzar la ley y "civilizar" a los pobladores mediante la educación implicaba aumentar y diferenciar los controles impuestos por el Estado sobre los individuos. Reavivar el sentimiento nacional suponía un ejercicio de las normas y los modales más exigentes ${ }^{65}$.

Paralelamente, se plantearía una reformulación de la codificación que regía en los territorios. En 1918, Ruiz Moreno y Nicanor D'Elia intentaron sin éxito reformar el Código Rural. Con especial énfasis, reconsideraban la vigencia del artículo 253. En el proyecto, se explicaba que

(...) dado el despoblamiento que existe en los territorios nacionales, no nos ha parecido prudente prohibir la portación de armas en la campaña, pero sí en los lugares poblados. El código actual no hace diferencia alguna sobre el particular, sin duda porque cuando se sancionó, había un número muy reducido de pueblos en los territorios ${ }^{66}$.

La prohibición regiría para los poblados con municipalidades o comisiones de fomento. Fuera de ellas, la policía no podía "prohibir o restringir el derecho de llevar armas, y en 
consecuencia, ninguna persona será registrada en la campaña, con el objeto de practicar averiguaciones al respecto" (Art. 485) ${ }^{67}$.

Cuatro años más tarde, Pasquini López, funcionario de uno de los tres juzgados del territorio, dictó una extensa resolución sobre los alcances y límites de la reglamentación en materia de armas. A juzgar por su intervención en las causas judiciales, el uso excedía ampliamente los casos de defensa propia, y eso conllevaba a hechos lamentables. El juez concluía que el Código Rural dictado para otros tiempos necesitaba una nueva interpretación. Sus normas habían sido creadas para condiciones de vida que habían cambiado en el territorio ${ }^{68}$.

En contextos donde tantos sujetos se negaban o se resistían a aceptar que las peleas y las armas fuesen una transgresión, encauzar la costumbre en el marco de la ley implicaba desposeerlos de una parte de sí, de esa masculinidad hecha de peleas y puñaladas. Así entonces, en 1922, el jurista proponía darle poder a la policía para determinar quién podía y quién no portar arma ${ }^{69}$. Eso implicaba modificar el criterio establecido por el Código Rural sobre la imposibilidad de restringir su uso.

Frente a la autorización de carácter general de llevar armas que esbozaba el artículo 253, el magistrado sugería que la policía fuese la encargada de proceder "empeñosamente" en el secuestro de toda arma. Al momento de retener un arma, el agente debía labrar un acta donde constara el lugar del secuestro, la fecha, el detalle del artefacto de fuego y las demás circunstancias que considerara necesarias en tal documento. Una vez confeccionada el acta, debía remitirla por intermedio de la jefatura al juez letrado de turno.

Que el procedimiento de secuestrar armas a viva fuerza a quien se resistiere a entregarlas no es punible. Exceptuase a todo vecino que habite en lugares distantes de centros poblados o que por sus ocupaciones tenga que alejarse de los mismos, debiendo solicitar el permiso al comisario departamental, el que deberá llevar la firma de dicho funcionario, el sello de la comisaría y la fecha de otorgamiento ${ }^{70}$.

La policía sería la institución que habilitaría el uso del arma; en ella recaía la responsabilidad de comprobar los antecedentes y la reputación del solicitante antes de entregar el permiso. Cuando éstos fueran otorgados a personas que, por su profesión (como carniceros, cazadores, etc.), estuvieran autorizadas para el uso del arma, se haría constar en tales permisos que su utilización no era permanente, sino solo dentro de las horas de trabajo de sus oficios.

No extraña que en la gestión de dicho certificado abundaran denuncias de favoritismos y actitudes antojadizas del comisario en cuestión. Teniendo en cuenta la discrecionalidad de las prácticas policiales, la normativa aconsejaba y recomendaba a todo el personal "ponerse espacial atención a fin de que no abusen los comisarios departamentales del permiso para portar armas, debiendo también dar terminantes instrucciones a la gendarmería y demás empleados para que estos no cometan abusos o violencias de ninguna índole"71.

59 Además de emitir los permisos, los comisarios y demás empleados de la repartición debían tomar medidas "a fin de que la población se compenetre de la necesidad de no usar armas y evitar así casos extremos de intervención policial, medidas más bien que serán de persuasión empleando para ello los términos que no degeneren en autoritarios y abusivos"72.

60 De acuerdo con la opinión del juez, los delitos con armas ocurrían, en particular, en el contexto rural y, específicamente, dentro del segmento social más bajo. Sobre la base 
de lo anterior, argumentaba que aumentar la densidad de la población y las líneas de comunicación garantizaría la disminución del mal de las armas. La gran densidad de las ciudades en contraposición al campo sería "un contralor seguro y eficiente de los actos criminales que se cometen, lo que no ocurre donde existen grandes extensiones deshabitadas que favorecen la impunidad de los delitos"73. En la década de 1920, una época marcada por una alta conflictividad social se trataba de una política destinada a establecer un control urbano más firme sobre el mundo rural.

La prensa acompañó la propuesta del juez, lanzando una encendida campaña contra la circulación y portación de armas blancas o de fuego. Sobre la base de un pacto tácito entre periodista y lector, la opinión pública se unía en los años '20 en contra de la proliferación de la violencia por fuera de la permitida al sujeto del Estado, el policía. Pero en verdad, la capital del territorio y epicentro de vida semiurbanizada era retratada en términos que no eran muy diferentes de los de la campaña. Historias de violencia y marginalidad se cruzaban en las calles y plazas de la ciudad o en los parajes rurales de los alrededores, que permitían ocultar al Moreira. Escuchar una detonación de un arma de fuego no llamaba la atención en Santa Rosa, por cuanto de mañana o de noche se sentían tiros.

Con frecuencia, no era la ciudad virtuosa, sino la ciudad violenta, la que retrataba $L a$ Autonomía; al punto de hacer inútil la dicotomía modernidad y tradición o civilización y barbarie con la que generalmente se la caracterizaba:

En pleno centro de la ciudad dos hombres libran una batalla a tiro limpio. Serían las once cuando se sintió un disparo de revólver seguido de un repicoteo que duró pocos minutos. Al pronto los que no se hallaban próximos al lugar del hecho dudaban si eran tales, pero bien pronto, por la corrida de policías y curiosos se pudo saber que se trataba de un hecho grave en la vereda de la calle Pellegrini se hallaba un hombre con una herida en la frente de la que manaba abundante sangre ${ }^{74}$.

Otro ejemplo disponible:

El uso y abuso de armas de fuego debe reprimirse pues ha llegado a ser tan general que nadie tiene segura su vida a la vuelta de cualquier esquina. Los muchachos, los niños y todo el mundo andan cargados a toda hora con revólver o pistola. En esta capital no debe pensarse en asaltos y robos en las calles durante el día ni aun de noche para ir tan armados, explicándose en consecuencia los accidentes y homicidios cuando a la más simple discusión sale a relucir el revólver para poner fin $^{75}$.

La Autonomía, mediante una eficaz interpelación a sus lectores, buscaba incorporarlos en su reclamo por una ley restrictiva del uso de las armas. Había que evitar al público las "molestias inútiles" del exhibicionismo armado porque, para los espectadores "civilizados", el alarde de la violencia no era más que un tonto y ridículo papel. En consecuencia, criticaban la ostentación de las armas como signo de cobardía ${ }^{76}$.

Pero los mecanismos represivos todavía eran insuficientes y poco aptos para contener dichas prácticas. Esto significaba para algunos sectores que frente a un referente policial débil y fragmentado, se antepusiera la fuerza coercitiva personal como único resguardo. De forma muy recurrente, podría leerse en la prensa: "se torna casi imposible por la ausencia semiabsoluta de seguridades para los moradores que se hallan en la poco envidiable situación de tener que confiar más en sus propias fuerzas que en el apoyo de las autoridades para afianzar su tranquilidad"77. Por tanto, el acto de ejercer justicia "por cuenta propia" continuó siendo avalado por importantes sectores de la sociedad, allí donde la tensión entre prohibir las armas o rendirse ante la 
costumbre estaba lejos de resolverse. Como ha expuesto Argeri para el territorio rionegrino, era frecuente que esos mismos vecinos "decentes" portaran armas ante lo que sentían como una amenaza constante. Por eso, cuando desde el poder nacional o local se pretendió restringir esta costumbre, argumentaban que se desconocía la realidad territoriana y se los dejaba en desventaja frente a la amenaza que, para muchos, representaban sus peones, los ocupantes circunstanciales y, también, la policía ${ }^{78}$.

Los reclamos por la ausencia y la ineficacia de las fuerzas policiales para dar protección generaron extendidos períodos de crisis de autoridad. De manera similar a lo señalado para el caso de Chubut, cuando el Estado por momentos era débil para imponer su legitimidad, pero también durante los períodos en que desplegaba su fortaleza mediante el uso de la violencia, tampoco se correspondía con las normas de civilidad establecidas con las que debían actuar los policías ${ }^{79}$. En abierta oposición a la arbitrariedad tan común en los pequeños resortes de la policía, una creciente "atmósfera de franca repulsión a la autoridad" impregnaba el territorio ${ }^{80}$. Las modalidades utilizadas por los policías "compadres" y "atropelladores" para resolver los conflictos incluían la fuerza del machete. Contrariamente, expresaba el diario La Autonomía, "en época de civilización no son tolerables estos episodios"

En ese amplio repertorio de acciones que transgredían la norma, un policía no sería ejemplar ni bueno, mientras "no se amuralle dentro de los límites que le están marcados", o dentro de los sentimientos que "forman parte del patrimonio de toda sociedad civilizada" 82 . Estas concepciones no venían sino a replicar modelos instaurados para ese "otro" sector de la población en vías de disciplinar -"si a quienes se les confía la custodia de los vecindarios son los que alteran el principio de garantía ¿qué queda para los que esa misma autoridad debe reprimir?". En este marco, una pregunta circulaba entre los pobladores: “¿quién ha dotado a unos de autoridad para matar a otro?”\$3. Al decir de Benjamin, ¿qué violencia está legitimada y cuál no? ${ }^{84}$.

Como se puede apreciar, existía un cúmulo de tensiones donde los sujetos participaban con conciencia de sus intereses y de sus limitaciones; negociaban con las autoridades los límites de la intervención; le cambiaban el significado; y, en algunos casos, se oponían a esa interferencia ${ }^{85}$. Los años veinte crearon un clima propicio para pedir, desde distintas esferas, la represión del uso de las armas. El proceso de privatización de la violencia se basaba en el fortalecimiento de la capacidad del Estado para ejercer una violencia más grande que desalentara la agresión que estaba prohibida para los otros ${ }^{86}$. En el caso que nos ocupa, la ambigüedad legal fue uno de los elementos que contribuyó a obstaculizar el monopolio estatal de la coacción afectando el proceso de construcción de la autoridad policial. De esta manera, se continuó utilizando la violencia en la arena pública porque aún no podía ser dominada por la policía para impartirla de manera profesional e impersonal. El protagonismo que adquirieron las actitudes y valores civilizados fue una de las marcas distintivas del proceso de cambio social de los años de entreguerras, que repercutió en lo que se decía y pensaba sobre el ejercicio de la violencia legítima, la policial.

\section{Conclusiones}

Construir un orden legítimo y, con él, desplegar un aparato de contención constituido por un cuerpo de funcionarios reconocidos y aceptados socialmente era una tarea harto 
difícil en el temprano siglo XX pampeano. Para construir un aparato de dominación legítimo había que apoyarse en la compleja y móvil sociedad, para luego procurar alejarse de ella según las lógicas del Estado ${ }^{87}$, las órdenes del gobierno y los intereses de distintos sectores que excedían a los grandes propietarios (como maestros, dirigentes políticos, periodistas, comerciantes, vecinos...).

70 La pacificación de una sociedad ha sido una temática de considerable interés para la historiografía. Es interesante notar que, en Argentina, otros historiadores que reconstruyeron las lógicas y dinámicas de las violencias para espacios, como la campaña bonaerense, han expresado que la criminalidad rural emergía de la conflictiva relación entre el Estado y los paisanos. En forma adicional, han planteado como la persistencia de usos y prácticas violentas no implicó considerar a esa sociedad como estática. Con todo, estas investigaciones centradas en el rol de la justicia de paz y letrada han observado como ambas esferas se constituyeron en uno de los mecanismos fundamentales de disciplinamiento de los habitantes en el ámbito rural ${ }^{88}$.

71 En el presente estudio se propuso una lectura diferente del uso de la violencia. Se optó por profundizar en las violencias extrajudiciales con el fin de cristalizar la configuración de la figura policial como representante del Estado. Así, se ensayaron aproximaciones que procuraron develar cómo convencer y habituar a la población a regular sus conflictos en el marco de la ley demandó muchos años. Se ha mencionado que, en el largo plazo, la ambigüedad legal entorpeció el monopolio del uso de la fuerza legítima en manos de la policía.

72 Si se la juzga por los números de delitos, la apuesta de monopolizar la violencia distó de ser exitosa, aunque fue mostrando mejores resultados en las décadas de 1920 y 1930. Como lo atestiguan los procesos judiciales, los usos de armas blancas y de fuego constituían un alto porcentaje de la totalidad de los delitos contra las personas. A lo largo del período, el crecimiento demográfico acompañará la curva ascendente de causas registradas contra las personas, y por ende relativiza la difusión de casos. A pesar de que el Estado desplegó su control sobre el territorio, las expresiones informales de justicia no desaparecieron. Estas prácticas de la violencia penetraron en el Estado disipando los límites que las distinguían. Y de ese modo, el uso de la fuerza física derivado de los valores tradicionales y las nociones de género confluyó tanto en los sujetos a disciplinar como en los policías.

73 En referencia a los sectores sociales involucrados, si bien se evidencia que es ampliamente variada la situación económica y social de víctimas y victimarios; el universo social estaba mayoritariamente compuesto por hombres de sectores populares. La mirada sobre los usuarios del sistema policial y judicial muestra así un conglomerado bastante complejo y diversificado, ya que claramente no se circunscribía a los sectores propietarios, como han sostenido en esta misma dirección otros estudios ${ }^{89}$.

De hecho, la intensificación de las denuncias por casos de lesiones entre 1920 y 1930 estaría indicando la preponderancia estatal ante la resolución de conflictos. En el transcurso de esas décadas y transversal al momento de reformas policiales, el proceso de institucionalización avanzó en pos de erradicar de manos privadas el acto de hacer justicia. Un estudio comparativo de la violencia entre los Estados Unidos y América Latina sostiene que las reformas policiales generalmente no ocurrieron hasta la década de los veinte. Los autores infieren que la "modernización" de la policía sucedió, principalmente, porque las elites presionaron por un mejor control para contener los 
disturbios y reforzar el orden social. Aun así, la mayoría de los países latinoamericanos no tuvieron éxito (o algunos solo temporalmente) en trasformar la policía en un representante confiable del poder del Estado legal ${ }^{90}$. En el caso que nos ocupa, la policía llevó adelante limitados intentos de reforma en varios sentidos. Si bien durante esa década no se logró profesionalizar a sus hombres y sus prácticas, fue el puntapié inicial de cambios que se consumarían en años posteriores.

Como hemos visto, la pacificación general no era beneficio de un solo sector, excedía los intereses de los grandes propietarios. De modo que el Estado, acompañado de los intereses de los sectores con mayor incidencia política, económica y social, buscó efectivizar el monopolio de la violencia. Como indica L'Heulliet, si la policía no es aceptada, difícilmente el Estado pueda mantener el orden por su naturaleza simbólica ${ }^{91}$. Así, algunos grupos, como el periodismo y la justicia letrada, ejercieron influencia directa y sistemática en la merma de la violencia. En su retórica, promovían valores que fortalecieran el proceso civilizatorio bajo distintos mecanismos, como la educación, la reformulación de los códigos vigentes y, más a menudo, el represivo. De esta manera, la construcción de la figura policial y su autoridad se consolidaron cuando las instituciones estatales lograron reemplazar el poder personal (con su capacidad de generar violencia).

\section{Fuentes}

\section{Archivo Histórico Provincial de La Pampa, Santa Rosa, Argentina}

Fondo de Gobierno, Expedientes varios, 1885-1930.

Justicia Letrada Nacional Secretaría en lo Penal, Expedientes Cajas nº1-7, 1885-1907.

Justicia Letrada Nacional del Crimen, Expedientes Cajas nº 1-34, 1907-1921.

Justicia Letrada Nacional del fuero Penal n ${ }^{\circ}$, Expedientes Cajas n¹-27, 1921-1951.

Órdenes del Día, libros 1- 50 (1900-1928)

\section{Hemeroteca}

La Capital, Santa Rosa, 1897-1906.

La Autonomía, Santa Rosa, 1918-1928.

\section{Biblioteca del Congreso de la Nación, Buenos Aires, Argentina}

Proyecto de Código Rural para los Territorios Nacionales de la República Argentina presentado al Poder Ejecutivo de la Nación, Imprenta Las Ciencias, Buenos Aires, 1919.

77 Código Rural para los Territorios Nacionales, Recopilación realizada por Máximo Reyna, 1902-1910. Ministerio del Interior, Buenos Aires, 1910.

\section{Biblioteca Nacional, Buenos Aires, Argentina}

Gadano, J. E., Territorios Nacionales, estudio político-económico, Avelardo, Buenos Aires, 1945. 


\section{BIBLIOGRAFÍA}

\section{Hemeroteca}

Revista de Policía, Buenos Aires, 1921-1922.

Lluch, Andrea (Ed.), Memorias de Gobernadores del Territorio Nacional de La Pampa, siglo XIX, Volumen I, Edulpam-Gobierno de la Pampa, Santa Rosa, 2005.

Lluch, Andrea (Ed.), Memoria de Gobernadores del Territorio Nacional de La Pampa, 1900-1920, Siglo XX, Volumen II, Edulpam, 2006, Santa Rosa.

Argeri, María Eva, De guerreros a delincuentes. La desarticulación de las jefaturas indígenas y el poder judicial. Nordpatagonia, 1880-1930, Consejo Superior de Investigaciones Científicas, Madrid, 2005. $331 \mathrm{p}$.

Barreneche, Osvaldo, "Del 'expediente judicial' a las disposiciones 'estrictamente secretas y confidenciales'. Itinerarios historiográficos sobre los archivos y fuentes históricas de la justicia y las instituciones de seguridad y del castigo en la Argentina", Revista Electrónica de Fuentes y Archivos, n6, Córdoba, 2015, pp. 13-25.

Barry, Viviana, Orden en Buenos Aires. Policías y modernización policial, 1890-1910, Tesis de Maestría en Historia, Universidad Nacional de San Martín, Buenos Aires, Argentina, 2009. 200 p.

Benjamín, Walter, "Para una crítica de la violencia”, Iluminaciones IV, Taurus, Buenos Aires, 1995. $165 \mathrm{p}$.

Bohoslavky, Ernesto, Bang-bang. El mundo del delito en el Territorio del Neuquén, 1900-1930, Tesis de Licenciatura en Historia, Universidad Nacional del Comahue, Neuquén, Argentina, 1998. 94 p.

Bohoslavsky, Ernesto, "La incurable desidia y la ciega imprevisión argentina. Notas sobre el Estado, 1880-1930", en: Vilas, Carlos (Ed.), Estado y política en la Argentina actual, Prometeo, Buenos Aires, 2005, pp. 107-129.

Bonaudo, Marta \& Bandieri, Susana, “La cuestión social agraria en los espacios rurales”, en: Falcón, Ricardo (Dir.), Nueva Historia Argentina, Tomo 6: "Democracia, conflicto social y renovación de ideas (1916-1930)”, Sudamericana, Buenos Aires, 2000, pp. 230-281.

Caimari, Lila, Mientras la ciudad duerme. Pistoleros, policías y periodistas en Buenos Aires, 1920-1945, Siglo XXI, Buenos Aires, 2012. 244 p.

Cárdenas, Vania, “Tras los pasos del ordenamiento policial: oscilaciones en torno a la violencia. Valparaíso 1896-1920”, Revista Historia y Justicia, n², Santiago de Chile, 2014, pp. 1-28.

Chasteen, John, "Violence for Show. Knife on a Nineteenth Century Cattle Frontier", en: Johnson, Lyman (ed.), The Problem of Order in Changing Societies, University of New Mexico Press, Albuquerque, 1990, pp. 47-64.

Carrizo, Gabriel \& Baeza, Brígida, "El mundo del delito en la Patagonia Central: medidas estatales y respuestas populares", en XI Jornadas Interescuelas/Departamentos de Historia, Facultad de Filosofía y Letras, Universidad Nacional de Tucumán, Tucumán, 2007.

Corva, María Angélica, “'Rastreando huellas'. La búsqueda de documentos judiciales para la investigación histórica”, Revista Electrónica de Fuentes y Archivos, n6, Córdoba, 2015, pp. 43-65. 
Di Liscia, María Silvia \& Lluch, Andrea, "La población pampeana y sus transformaciones", en: Lluch, Andrea \& Salomón Tarquini, Claudia (Comps.), Historia de La Pampa, sociedad, política, economía, desde los doblamientos iniciales hasta la provincialización: ca. 8.000 ap. a 1952, Edulpam, Santa Rosa, 2008, pp. 115-128.

Diez, María Angélica, Criminalidad y justicia en la sociedad pampeana entre 1885 y 1905. El delito contra las personas: una imagen de las relaciones y conflictos interpersonales, Tesis de Licenciatura en Historia, Universidad Nacional de La Pampa, Santa Rosa, Argentina, 1998. 207 p.

Diez, María Angélica; Vincens, Daniela; Calderon, Silvana; Jil Mandujano, Susana \& Ferrari, Jorge, "Conflictos y delitos en la etapa de formación de la sociedad pampeana (1885-1922)", en: Colombato, Julio (Coord.), Trillar era una fiesta. Poblamiento y puesta en producción de La Pampa territoriana, Tomo II, Fondo editorial Pampeano, Santa Rosa, 1995, pp. 13-70.

Elias, Norbert, El proceso de la civilización. Investigaciones sociogenéticas y psicogenéticas, Fondo de Cultura Económica, México, 1987. 686 p.

Farge, Arlette, "Algunos instrumentos para reflexionar sobre la historia de la violencia" Anuario Instituto de Estudios Históricos y Sociales, n¹0, Tandil, 1995, pp. 145-154.

Farge, Arlette, Efusión y tormento. El relato de los cuerpos. Historia del pueblo en el siglo XVIII, Katz, Buenos Aires, 2008. 235 p.

Fernández, María Alejandra, "Desafíos y potencialidades del archivo judicial: conflictos interpersonales, honor y justicia en Hispanoamérica", Revista Electrónica de Fuentes y Archivos, n9, Córdoba, 2018, pp. 40-61.

Fernández Marrón, Melisa, “Cartografías policiales. El lugar de la comisaría en La Pampa argentina de fines del siglo XIX y principios del XX”, en: Salvatore, Ricardo \& Barreneche, Osvaldo (Comp.), El delito y el orden en perspectiva histórica. Nuevos aportes a la historia de justicia penal y las instituciones de seguridad en Argentina, Prohistoria, Rosario, 2013, pp. 139-166.

Fernández Marrón, Melisa, “Los trabajos y los días: la rutina policial en La Pampa Argentina (1884-1930)", en: Moroni, Marisa; Casullo, Fernando \& Carrizo, Gabriel (Eds.), Justicia, seguridad y castigo. Concepciones y prácticas en la Patagonia: 1884-1955, Prohistoria Ediciones-EdUNLPam, Rosario, 2018, pp. 147-168.

Fernández Marrón, Melisa, “Policías en el mundo rural pampeano: reclutamiento y mercado de trabajo (Territorio Nacional de La Pampa, 1884-1920)", Estudios Sociales del Estado, Vol. 4, n7, Buenos Aires, 2018, pp. 124-150.

Fradkin, Raúl, “Entre la ley y la práctica: la costumbre en la campaña bonaerense de la primera mitad del siglo XIX”, Anuario Instituto de Estudios Históricos y Sociales, Tandil, n²12, 1997, pp. 141-156.

Fradkin, Raúl, "Ley, costumbre y relaciones sociales en la campaña de Buenos Aires (siglos XVIII y XIX”, en: Fradkin, Raúl (Comp.), La ley es tela de araña. Ley, justicia y sociedad en Buenos Aires, 1780-1830, Prometeo, Buenos Aires, 2009, pp. 121-158.

Fréderic, Sabina, “Oficio policial y usos de la fuerza pública: aproximaciones al estudio de la policía de la provincia de Buenos Aires”, en: Bohoslavsky, Ernesto \& Soprano, Germán (Eds.), Un Estado con rostro humano. Funcionarios e instituciones estatales en Argentina (desde 1880 a la actualidad), Prometeo, Buenos Aires, 2010, pp. 281-307.

Garavaglia, Juan Carlos, "Paz, orden y trabajo en la campaña: la justicia rural y los juzgados de paz en Buenos Aires, 1830-1852”, Desarrollo Económico, Vol. 37, n¹46, Buenos Aires, 1997, pp. 57-87. 
Garland, David, Castigo y sociedad moderna. Un estudio de teoría social, Siglo XXI, México, 2006. 361 p.

Gayol, Sandra, Honor y duelo en la Argentina moderna, Siglo XXI, Buenos Aires, 2008. 288 p.

Gelman, Jorge, “Crisis y reconstrucción del orden en la campaña de Buenos Aires. Estado y sociedad en la primera mitad del siglo XIX", Boletín del Instituto de Historia Argentina y Americana Dr. Emilio Ravignani, n²1, Buenos Aires, 2000, pp. 7-31.

Hartmut, Keil \& Riekenberg, Michael, "Violence in the United States and Latin America in the Nineteenth Century: A Comparative Approach”, Iberoamericana, n4, Berlin, 2001, pp. 45-67.

Johnson, Lyman, "Dangerous Words, Provocative Gestures, and Violent Acts. The Disputed Hierachies of Plebeian Life in Colonial Buenos Aires", en: Johnson, Lyman \& Lipsett-Rivera, Sonya (Eds.), The Face of Honor. Sex, Shame and Violence in Colonial Latin America, Albuquerque, University of New Mexico Press, 1998, pp. 127-151.

Laera, Alejandra, El tiempo vacío de la ficción. Las novelas argentinas de Eduardo Gutiérrez y Eugenio Cambaceres, Fondo de Cultura Económica, Buenos Aires, 2003. 342 p.

L'Heulliet, Hélène, Baja política, alta policía. Un enfoque histórico y filosófico de la policía, Prometeo, Buenos Aires, 2010. 368 p.

Lluch, Andrea, “La economía desde la ocupación capitalista a la crisis del '30 y los años posteriores", en Lluch, Andrea \& Salomón Tarquini, Claudia (Comp.), Historia de La Pampa, sociedad, política, economía, desde los doblamientos iniciales hasta la provincialización: ca. 8.000 ap. a 1952, Edulpam, Santa Rosa, 2008, pp. 133-161.

Ludmer, Josefina, El cuerpo del delito. Un manual, Eterna Cadencia, Buenos Aires, 2011. 524 p.

Malcolm, Joyce Lee, Guns and Violence. The English Experience, Harvard University Press, Cambridge, 2000. $352 \mathrm{p}$.

Maluendres, Sergio, "Los agricultores de los márgenes de la región pampeana: mitos y realidades. El caso del Territorio Nacional de La Pampa", en: Bjerg, Mónica \& Reguera, Andrea (comp.), Problemas de historia agraria. Nuevos debates y perspectivas de investigación, Instituto de Estudios Históricos y Sociales, Tandil, 1995, pp. 183-209.

Mari, Oscar, "Milicias, delito y control estatal en el Chaco (1884-1940)", Mundo Agrario, n¹1, La Plata, 2006. Disponible en: http://www.mundoagrario.unlp.edu.ar/numeros/numero11/ [Fecha de consulta: 1 de abril de 2019]

Mauch, Claudia, "Masculinidad y violencia en la construcción de la autoridad policial en el inicio del siglo XX en el sur de Brasil”, en: Bohoslavsky, Ernesto; Caimari, Lila \& Schettini, Cristiana (Comp.), La policía en perspectiva histórica: Argentina y Brasil desde el siglo XIX a la actualidad, Ediciones del Autor, Buenos Aires, 2009.

Monjardet, Dominique, Lo que hace la policía. Sociología de la fuerza pública, Prometeo, Buenos Aires, 2010. $364 \mathrm{p}$.

Moroni, Marisa, “Orden social, delito y castigo en el Territorio Nacional de La Pampa, 1920-1930", en: Casullo, Fernando; Gallucci, Lisandro \& Perren, Joaquín (Comp.), Los estados del Estado. Instituciones y agentes estatales en la Patagonia, 1880-1940, Prohistoria, Rosario, 2013, pp. 43-62.

Moroni, Marisa, "Las demandas de seguridad y la articulación con los reclamos de autonomía política en el territorio nacional de La Pampa en las primeras décadas del siglo XX”, en: Palma Alvarado, Daniel (Comp.), Delincuentes, policías y justicias en América Latina, siglos XIX y XX, Ediciones Universidad Alberto Hurtado, Chile, 2015, pp. 260-275. 
Núñez Cetina, Saydi, “La violencia, el pulque y la muerte. Criminalidad y castigo en México entre 1920-1940”, Historia 2.0. Conocimiento Histórico en Clave Digital, n6, México, 2013, pp. 144-157.

Oliver Olmo, Pedro, "Orden, violencia y Estado. El concepto de control social en la historia social: estructuración del orden y respuestas al desorden”, Historia Social, n51, Valencia, 2005, pp. 73-91.

Palacio, Juan Manuel, “Hurgando en las bambalinas de 'la paz del trigo': Algunos problemas teórico-metodológicos que plantea la historia judicial”, Quinto Sol, n9-10, Santa Rosa, 2005-2006, pp. 99-123.

Pulido Esteva, Diego, "Profesional y discrecional: policía y sociedad en la ciudad de México del Porfiriato a la posrevolución", Antropología. Boletín oficial del Instituto Nacional de Antropología e Historia, n94, México, 2012, pp. 72-85.

Rafart, Gabriel, Tiempo de violencia en la Patagonia, Bandidos, policías y jueces (1890-1940), Prometeo, Buenos Aires, 2008. 233 p.

Rodríguez Molas, Ricardo, Historia social del gaucho, Centro Editor de América Latina, Buenos Aires, 1982. $301 \mathrm{p}$.

Salvatore, Ricardo, Subalternos, derechos y justicia penal. Ensayos de historia social y cultural argentina 1829-1940, Gedisa, Barcelona, 2010. 353 p.

Salvatore, Ricardo, Wandering Paysanos. State Order and Subaltern Experience in Buenos Aires during the Rosas Era, Duke University Press, Durham, 2003. 544 p.

Salvatore, Ricardo, “Sobre el surgimiento del Estado médico-legal en Argentina (1890-1940)", Estudios Sociales, $\mathrm{n}^{\circ} 20$, Santa Fe, 2003, pp. 81-114.

Saítta, Sylvia, Regueros de tinta. El diario Crítica en la década de 1920, Sudamericana, Buenos Aires, 1998. $316 \mathrm{p}$.

Sckopol, Theda, Los Estados y las revoluciones sociales, Fondo de Cultura Económica, México, 1984. $501 \mathrm{p}$.

Schwerhoff, G., "Criminalized Violence and the Process of Civilization: A Reappraisal", Crime, Histoire \& Sociétés/Crime, History \& Societies, Vol. 6, n², 2002, pp. 103-126.

Sedeillán, Gisella, "El papel de la policía de la provincia de Buenos Aires en la instrucción sumarial en el período de codificación del derecho", en: Bohoslavsky, Ernesto; Caimari, Lila \& Schettini, Cristiana (Comp.), La policía en perspectiva histórica: Argentina y Brasil desde el siglo XIX a la actualidad, Ediciones del Autor, Buenos Aires, 2009.

Sedeillán, Gisella, "La penalidad de la ebriedad en el código penal y en la praxis judicial bonaerense: 1878-1888”, Anuario del Instituto de Historia Argentina, n8, La Plata, 2008, pp. 151-171. Slatta, Richard, Los gauchos y el ocaso de la frontera, Sudamericana, Buenos Aires, 1985. 367 p. Slatta, Richard, "Rural Criminality and Social Conflict in Nineteenth-Century Buenos Aires Province”, Hispanic American Historical Review, Vol. 60, n³, 1980, pp. 452-472.

Slatta, Richard \& Robinson, Karla, "Continuities in Crime and Punishment. Buenos Aires, 1820-50", en: Johnson, Lyman (comp.), The Problem of Order in Changing in Societies: Essays of Crime and Policing in Argentina and Uruguay, 1750-1940, University of New Mexico, Albuquerque, 1990, pp. 18-45.

Spierenburg, Peter, "Violence and the Civilizating Process: Does it Work?" Crime, Historie \& Société/Crime, History \& Societies, vol. 5, 2001, p. 87-105. 
Yangilevich, Melina, Estado y criminalidad en la frontera sur de Buenos Aires (1850-1880), Rosario, Prohistoria, 2012. $232 \mathrm{p}$.

Yangilevich, Melina \& Miguez, Eduardo, "Justicia criminal y Estado en la frontera de Buenos Aires, 1852-1880", Boletín del Instituto de Historia Argentina y Americana Emilio Ravignani, n³2, Buenos Aires, 2010, pp. 107-137.

\section{NOTAS}

1. En 1884, en Argentina, la organización política interna de los Territorios Nacionales (Chaco, Chubut, Formosa, Misiones, Neuquén, La Pampa, Río Negro, Santa Cruz, Tierra del Fuego y el Territorio de los Andes) quedó definida a partir de la promulgación de la Ley no1532.

2. Véase, Fernández Marrón, Melisa, "Policías en el mundo rural pampeano: reclutamiento y mercado de trabajo (Territorio Nacional de La Pampa, 1884-1920)", Estudios Sociales del Estado, Vol. 4, n7, Buenos Aires, 2018, pp. 124-150; Fernández Marrón, Melisa, “Los trabajos y los días: la rutina policial en La Pampa Argentina (1884-1930)”, en: Moroni, Marisa; Casullo, Fernando \& Carrizo, Gabriel (Eds.), Justicia, seguridad y castigo. Concepciones y prácticas en la Patagonia: 1884-1955, Prohistoria Ediciones/EdUNLPam, Rosario, 2018, pp. 147-168.

3. Gelman, Jorge, "Crisis y reconstrucción del orden en la campaña de Buenos Aires. Estado y sociedad en la primera mitad del siglo XIX", Boletín del Instituto de Historia Argentina y Americana Dr. Emilio Ravignani, n²1, 2000, Buenos Aires, pp. 23-26.

4. Monjardet, Dominique, Lo que hace la policía. Sociología de la fuerza pública, Prometeo, Buenos Aires, 2010, pp. 25-29.

5. Sckopol, Theda, Los Estados y las revoluciones sociales, Fondo de Cultura Económica, México, 1984, p. 55.

6. Archivo Histórico Provincial La Pampa (en adelante, AHPLP), Fondo de Gobierno (en adelante, FG), caja (en adelante, C) 2, 10 de diciembre de 1887. El Código Penal de la Nación (Ley n ${ }^{\circ}$ 1920), promulgado el 7 de noviembre de 1886, introdujo esta figura en el artículo n ${ }^{\circ} 99$.

7. Biblioteca del Congreso Nacional (en adelante, $\mathrm{BCN}$ ), Código Rural para los Territorios Nacionales, Recopilación realizada por Máximo Reyna, 1902-1910, Ministerio del Interior, Buenos Aires, 1910.

8. El Código Penal de 1886 fue reemplazado por la Ley $n^{\circ} 11179$, sancionada el 30 de septiembre de 1921.

9. Al respecto, Arlette Farge afirma, "en alguna parte, esa activa febrilidad de cada día y en las frecuentes violencias, podemos entrever que los habitantes, en su carencia de poder, buscan enunciar uno -o muchos- derecho(s)". Farge, Arlette, Efusión y tormento. El relato de los cuerpos. Historia del pueblo en el siglo XVIII, Katz, Buenos Aires, 2008, p. 96.

10. Oliver Olmo, Pedro, "Orden, violencia y Estado. El concepto de control social en la historia social: estructuración del orden y respuestas al desorden”, Historia Social, n51, Valencia, 2005, pp. 89-90. Para un estudio comparativo sobre la violencia en América, véase: Hartmut, Keil \& Michael Riekenberg, "Violence in the United States and Latin America in the Nineteenth Century: A Comparative Approach", Iberoamericana, n4, Berlín, 2001, pp. 45-67.

11. Véase: Slatta, Richard, Los gauchos y el ocaso de la frontera, Sudamericana, Buenos Aires, 1985; y del mismo autor, "Rural Criminality and Social Conflict in Nineteenth-Century Buenos Aires Province”, Hispanic American Historical Review, vol. 60, n³, 1980, pp. 452-472; Rodríguez Molas, Ricardo, Historia social del gaucho, Centro Editor de América Latina, Buenos Aires, 1982.

12. Véase, entre otros, Fradkin, Raúl, "Entre la ley y la práctica: la costumbre en la campaña bonaerense de la primera mitad del siglo XIX", Anuario IEHS, n¹2, Tandil, 1997, pp. 141-156; Fradkin, Raúl, "Ley, costumbre y relaciones sociales en la campaña de Buenos Aires (siglos XVIII y XIX)”, en: Fradkin, Raúl (Comp.), La ley es tela de araña. Ley, justicia y sociedad en Buenos Aires, 
1780-1830, Prometeo, Buenos Aires, 2009, pp. 121-158; Gelman, J., “Crisis y reconstrucción del orden”, Op. Cit.; Garavaglia, Juan Carlos, "Paz, orden y trabajo en la campaña: la justicia rural y los juzgados de paz en Buenos Aires, 1830-1852”, Desarrollo Económico, vol. 37, n¹46, Buenos Aires, 1997, pp. 57-87.

13. Salvatore, Ricardo, Subalternos, derechos y justicia penal. Ensayos de historia social y cultural argentina 1829-1940, Gedisa, Barcelona, 2010; del mismo autor, Wandering Paysanos. State Order and Subaltern Experience in Buenos Aires during the Rosas Era, Duke University Press, Durham, 2003; Yangilevich, Melina, Estado y criminalidad en la frontera sur de Buenos Aires (1850-1880), Prohistoria, Rosario, 2012; Yangilevich, Melina \& Miguez, Eduardo, "Justicia criminal y Estado en la frontera de Buenos Aires, 1852-1880", Boletín del Instituto de Historia Argentina y americana Emilio Ravignani, n³2, Buenos Aires, 2010, pp. 107-137; Slatta, Richard \& Robinson, Karla, "Continuities in Crime and Punishment. Buenos Aires, 1820-50", en: Johnson, Lyman (Comp.), The Problem of Order in Changing in Societies: Essays of Crime and Policing in Argentina and Uruguay, 1750-1940, University of New Mexico, Albuquerque, 1990, pp. 18-45.

14. Argeri, María Eva, De guerreros a delincuentes. La desarticulación de las jefaturas indígenas y el poder judicial. Nordpatagonia, 1880-1930, Consejo Superior de Investigaciones Científicas, Madrid, 2005; Rafart, Gabriel, Tiempo de violencia en la Patagonia, Bandidos, policías y jueces (1890-1940), Prometeo, Buenos Aires, 2008; Bohoslavky, Ernesto, Bang-bang. El mundo del delito en el Territorio del Neuquén, 1900-1930, Tesis de Licenciatura en Historia, Universidad Nacional del Comahue, Neuquén, Argentina, 1998; Carrizo, Gabriel \& Baeza, Brígida, "El mundo del delito en la Patagonia Central: medidas estatales y respuestas populares", en XI Jornadas Interescuelas/Departamentos de Historia, Facultad de Filosofía y Letras, Universidad Nacional de Tucumán, Tucumán, 2007; Mari, Oscar, "Milicias, delito y control estatal en el Chaco (1884-1940)", Mundo Agrario, La Plata, $\mathrm{n}^{\circ} 11$, 2006. Disponible en: http://www.mundoagrario.unlp.edu.ar/numeros/numero11/ [Fecha de consulta: 1 de abril de 2019]

15. Para un análisis de la violencia en la historia, véase: Farge, Arlette, "Algunos instrumentos para reflexionar sobre la historia de la violencia", Anuario Instituto de Estudios Históricos y Sociales, $\mathrm{n}^{\circ}$ 10, Tandil, 1995, pp. 145-154.

16. AHPLP, Justicia Letrada Nacional Secretaría en lo Penal, 1885-1907 (en adelante, JLNSP), Justicia Letrada Nacional del Crimen, 1907-1921 (en adelante, JLNC) y Justicia Letrada Nacional del fuero Penal $n^{\circ} 1,1921-1951$ (en adelante, JLNP). Los criterios que se optaron para clasificar las acciones delictivas contra las personas no incluyen actos de violencia física (o tentativas) efectuados en el contexto de otro tipo de acciones delictivas, como podría ser en casos caratulados "robo y hurto". Asimismo, se han exceptuado de la muestra los casos de delitos contra la honestidad, el infanticidio, el aborto, el abandono de niños, el matrimonio ilegal, las calumnias e injurias, las lesiones por accidente y los delitos contra el estado civil y contra las garantías individuales.

17. Fernández, María Alejandra, "Desafíos y potencialidades del archivo judicial: conflictos interpersonales, honor y justicia en Hispanoamérica", Revista Electrónica de Fuentes y Archivos, n9, 2018, Córdoba, p. 44.

18. Para reflexionar acerca del grado de representatividad de los expedientes judiciales y de la amplitud o no de la muestra documental, como su tratamiento, véanse: Barreneche, Osvaldo, "Del 'expediente judicial' a las disposiciones 'estrictamente secretas y confidenciales'. Itinerarios historiográficos sobre los archivos y fuentes históricas de la justicia y las instituciones de seguridad y del castigo en la Argentina", Revista Electrónica de Fuentes y Archivos, n6, Córdoba, 2015, pp. 13-25; Corva, María Angélica, “'Rastreando huellas'. La búsqueda de documentos judiciales para la investigación histórica”, Revista Electrónica de Fuentes y Archivos, n6, Córdoba, 2015, pp. 43-65.

19. Fernández, M. A., “Desafíos y potencialidades del archivo judicial”, Op. Cit., p. 45. 
20. Palacio, Juan Manuel, “Hurgando en las bambalinas de 'la paz del trigo': Algunos problemas teórico-metodológicos que plantea la historia judicial”, Quinto Sol, n9-10, Tandil, 2005-2006, pp. 107-110.

21. AHPLP, JLNC, C 7, Expediente (en adelante, E) C-806, 13 de mayo de 1912.

22. Para una reconstrucción de la vida y obra de Juan Moreira, véase, Ludmer, Josefina, El cuerpo del delito. Un manual, Eterna Cadencia, Buenos Aires, 2011; Laera, Alejandra, El tiempo vacío de la ficción. Las novelas argentinas de Eduardo Gutiérrez y Eugenio Cambaceres, Fondo de Cultura Económica, Buenos Aires, 2003.

23. AHPLP, La Capital (en adelante, LC), 5 de septiembre de 1906; La Autonomía (en adelante, LA), 6 de enero de 1923.

24. Para más detalles sobre las condiciones socioeconómicas del territorio, véase: Maluendres, Sergio, "Los agricultores de los márgenes de la región pampeana: mitos y realidades. El caso del Territorio Nacional de La Pampa", en Bjerg, Mónica \& Reguera, Andrea (Comp.), Problemas de historia agraria. Nuevos debates y perspectivas de investigación, Instituto de Estudios Históricos y Sociales, Tandil, 1995, pp. 183-209; Lluch, Andrea, "La economía desde la ocupación capitalista a la crisis del '30 y los años posteriores”, en Lluch, Andrea \& Salomón Tarquini, Claudia (Comp.), Historia de La Pampa, sociedad, política, economía, desde los doblamientos iniciales hasta la provincialización: ca. 8.000 ap. a 1952, Edulpam, Santa Rosa, 2008, pp. 133-161.

25. Sobre las limitaciones de las estadísticas policiales, véase: Caimari, Lila, Mientras la ciudad duerme. Pistoleros, policías y periodistas en Buenos Aires, 1920-1945, Siglo XXI, Buenos Aires, 2012, p. 29.

26. Lluch, Andrea (Ed.), Memorias de gobernadores del Territorio Nacional de La Pampa, siglo XIX, Volumen I, Edulpam-Gobierno de la Pampa, Santa Rosa, 2005, p. 65; Lluch, Andrea (Ed.), Memoria de Gobernadores del Territorio Nacional de La Pampa, 1900-1920, Siglo XX, Volumen II, Edulpam, 2006, Santa Rosa, p. 138. AHPLP, FG, E 357 P, 12 marzo de 1926; E s/n, Santa Rosa, enero de 1935.

27. En el Código Penal de 1886, las lesiones corporales fueron definidas como "las heridas, los golpes, la administración de sustancias nocivas y cualesquiera otras lesiones cometidas voluntariamente" (Art. 114). Cita como ejemplos: sacar los ojos, castrar, mutilar un miembro o un órgano, o cuando por las lesiones el damnificado queda demente, inútil para el trabajo, impotente, impedido de algún miembro o deforme (Art. 119-121). En los casos de lesiones, las penas podían ir desde el arresto y la prisión hasta el confinamiento en una penitenciaria. En el Código Penal de 1921, se impondría prisión de acuerdo con la gravedad que un daño causase a otro en el cuerpo o en la salud; sí la lesión produjese una debilitación permanente de la salud, de un sentido, de un órgano, de un miembro o una dificultad permanente de la palabra o si hubiese puesto en peligro la vida del ofendido (Libro Segundo, Título I, Capítulo II, artículos 89-94).

28. Las causas fueron caratuladas de diversa manera respetándose la denominación original en la muestra: lesiones leves o graves con armas de fuego, agresión a mano armada, contusiones recíprocas, disparos de armas y homicidio, salvo en el caso de "lesiones", en el cual se incorporaron tanto las leves como las graves y aquellas tipificadas como "recíprocas" para no forzar una clasificación ad hoc que no sea representativa de la denominación original de la causa. 29. Diez, María Angélica; Vincens, Daniela; Calderón, Silvana; Jil Mandujano, Susana \& Ferrari, Jorge, "Conflictos y delitos en la etapa de formación de la sociedad pampeana (1885-1922)", en: Colombato, Julio (Coord.), Trillar era una fiesta. Poblamiento y puesta en producción de La Pampa territoriana, tomo II, Fondo editorial Pampeano, Santa Rosa, 1995, pp. 13-70.

30. Yangilevich, M. \& Miguez, E., "Justicia criminal y Estado", Op. Cit.

31. Di Liscia, María Silvia \& Lluch, Andrea, "La población pampeana y sus transformaciones", en: Lluch, Andrea \& Salomón Tarquini, Claudia (Comps.), Historia de La Pampa, sociedad, política, economía, desde los doblamientos iniciales hasta la provincialización: ca. 8.000 ap. a 1952, Edulpam, Santa Rosa, 2008, pp. 115-128.

32. Di Liscia, M. S. \& Lluch, A., “La población pampeana”, Op. Cit. 
33. En 1915, el mapa territoriano quedó escindido en 22 departamentos. A lo largo del período aquí estudiado, los principales centros urbanos como General Pico, Santa Rosa ciudad capital, Macachín, Guatrache, y Toay o Victorica se encontraban distribuidos en los departamentos 1, 2, 3 y 7 respectivamente.

34. Fernández Marrón, Melisa, “Cartografías policiales. El lugar de la comisaría en La Pampa argentina de fines del siglo XIX y principios del XX", en: Salvatore, Ricardo \& Barreneche, Osvaldo (Comp.), El delito y el orden en perspectiva histórica. Nuevos aportes a la historia de justicia penal y las instituciones de seguridad en Argentina, Prohistoria, Rosario, 2013, pp. 139-166.

35. AHPLP, JLNSP, C 6, E A-13, 29 de junio de 1904.

36. Otro ejemplo: AHPLP, JLNC, C 7, E A-10, 19 de junio de 1912. Véase Sedeillán, Gisella, "El papel de la policía de la provincia de Buenos Aires en la instrucción sumarial en el período de codificación del derecho", en: Bohoslavsky, Ernesto; Caimari, Lila \& Schettini, Cristiana (Comp.), La policía en perspectiva histórica: Argentina y Brasil desde el siglo XIX a la actualidad, Ediciones del Autor, Buenos Aires, 2009, p. 13.

37. AHPLP, JLNSP, C 6, E A-13, 29 de junio de 1904. El subrayado es nuestro.

38. Pulido Esteva, Diego, "Profesional y discrecional: policía y sociedad en la ciudad de México del Porfiriato a la posrevolución”, en Antropología. Boletín oficial del Instituto Nacional de Antropología e Historia, n94, México, 2012, pp. 72-85.

39. Sobre las concepciones del honor y la masculinidad en Argentina, véase: Gayol, Sandra, Honor y duelo en la Argentina moderna, Siglo XXI, Buenos Aires, 2008.

40. Diez, María Angélica, Criminalidad y justicia en la sociedad pampeana entre 1885 y 1905. El delito contra las personas: una imagen de las relaciones y conflictos interpersonales, Tesis de Licenciatura en Historia, Universidad Nacional de La Pampa, Santa Rosa, Argentina, 1998, pp. 153-154.

41. AHPLP, FG, E 429, 16 de marzo de 1925.

42. AHPLA, LA, 24 de abril de 1925. En el caso del Territorio Nacional del Chaco, durante los años treinta, la gobernación propuso como medida "el sábado inglés". El fin era reducir los espacios donde acontecían los encuentros de sangre. Véase, Mari, O., "Milicias, delito y control”, Op. Cit.

43. AHPLP, LA, 2 de marzo de 1921.

44. Esta estrategia no es privativa de los habitantes del espacio pampeano, sino que fue común a otros escenarios nacionales e internacionales. Para un análisis sobre las prácticas judiciales y sociales a partir de los procesos penales sobre homicidio en riña y el impacto del alcohol, véase entre otros: Yangilevich, M., Estado y criminalidad, Op. Cit.; Núñez Cetina, Saydi, "La violencia, el pulque y la muerte. Criminalidad y castigo en México entre 1920-1940", Historia 2.0. Conocimiento Histórico en Clave Digital, n6, México, 2013, pp. 144-157.

45. AHPLP, JLNC, C 2, E L-231. Un estudio sobre cómo la ley dejó márgenes para considerar la ebriedad como atenuante o no de la penalidad, Sedeillán, Gisella, "La penalidad de la ebriedad en el Código Penal y en la praxis judicial bonaerense: 1878-1888”, Anuario del Instituto de Historia Argentina, n8, La Plaza, 2008, pp. 151-171.

46. Chasteen, John, "Violence for show. Knife on a nineteenth century cattle frontier", en: Johnson, Lyman (ed.), The Problem of Order in Changing Societies, University of New Mexico Press, Albuquerque, 1990, pp. 47-64.

47. Para 1914, se registraban 5 casas dedicadas a la armería ubicadas en: Macachín ("Julio Sabatler, francesa"), Eduardo Castex ("Emiliano Rodríguez"), Santa Rosa ("Enrique Sturba", "Francisco Rodríguez"), Parera (“Julio Bouvignon") y Bernasconi ("Moisés Bonder")

48. Caimari, L., Mientras la ciudad duerme, Op. Cit., pp. 45-54.

49. Citado en Fréderic, Sabina, "Oficio policial y usos de la fuerza pública: aproximaciones al estudio de la policía de la provincia de Buenos Aires”, en: Bohoslavsky, Ernesto \& Soprano, Germán (Eds.), Un Estado con rostro humano. Funcionarios e instituciones estatales en Argentina (desde 1880 a la actualidad), Prometeo, Buenos Aires, 2010, p. 300.

50. AHPLP, LA, 27 de diciembre de 1921. 
51. AHPLP, LA, 21 de diciembre de 1928.

52. Elias, Norbert, El proceso de la civilización. Investigaciones sociogenéticas y psicogenéticas, Fondo de Cultura Económica, México, 1987. Asimismo, vease, Spierenburg, Peter, "Violence and the Civilizating Process: Does it Work?", Crime, Historie \& Sociétés/Crime, History \& Societies, Vol. 5, 2001, pp. 85-105; Schwerhoff, G., "Criminalized Violence and the Process of Civilization: A Reappraisal", Crime, Histoire \& Sociétés/Crime, History \& Societies, Vol. 6, n², 2002, p. 103-126.

53. AHP, LA, 27 de diciembre de 1921.

54. AHP, LA, 23 de mayo de 1921.

55. AHPLP, LC, 2 de septiembre de 1906.

56. Salvatore, Ricardo, "Sobre el surgimiento del Estado médico-legal en Argentina (1890-1940)", Estudios Sociales, $\mathrm{n}^{\circ} 20$, Santa Fe, 2003, pp. 81-114.

57. Caimari, L., Mientras la ciudad duerme, Op. Cit., pp. 65-66.

58. Sobre cómo la prensa construye estereotipos del "desorden", efectúa propuestas de acción y diseña respuestas desde el ámbito judicial para solucionar las cuestiones delictivas, véase: Moroni, Marisa, "Orden social, delito y castigo en el Territorio Nacional de La Pampa, 1920-1930", en: Casullo, Fernando; Gallucci, Lisandro \& Perren, Joaquín (Comps.), Los estados del Estado. Instituciones y agentes estatales en la Patagonia, 1880-1940, Prohistoria, Rosario, 2013, pp. 43-62; y de la misma autora, "Las demandas de seguridad y la articulación con los reclamos de autonomía política en el territorio nacional de La Pampa en las primeras décadas del siglo XX", en: Palma Alvarado, Daniel (Comp.), Delincuentes, policías y justicias en América Latina, siglos XIX y XX, Ediciones Universidad Alberto Hurtado, Chile, 2015, pp. 260-275.

59. AHPLP, LA, 1 de marzo, 4 de febrero, 6 de junio, 15 y 22 de julio, 19 y 28 de septiembre , 28 de noviembre de 1921; 4 de enero, 4 de mayo, 18 de abril, 19 de enero, 31 de marzo de 1923; 21 de junio de 1928; 18 de febrero de 1927.

60. Saítta, Sylvia, Regueros de tinta. El diario Crítica en la década de 1920, Sudamericana, Buenos Aires, 1998, p. 198.

61. Caimari, L., Mientras la ciudad duerme, Op. Cit., capítulo 2.

62. Garland, David, Castigo y sociedad moderna. Un estudio de teoría social, Siglo XXI, México, 2006, p. 277.

63. Durante la década de los veinte, se evidencian procesos similares para la regulación y apaciguamiento de las tensiones entre los hombres en los Territorios Nacionales de Neuquén y Chubut: Bohoslavky, E., Bang-bang. El mundo del delito", Op. Cit.; Carrizo, G. \& Baeza, B., "El mundo del delito en la Patagonia Central", Op. Cit. Mientras que para el caso chaqueño, hasta entrada la década de los treinta, los delitos contra las personas no parecieron constituir una cuestión excesivamente preocupante para las autoridades. Mari, O., "Milicias, delito y control estatal", Op. Cit.

64. Bonaudo, Marta \& Bandieri, Susana, "La cuestión social agraria en los espacios rurales", en: Falcón, Ricardo (Dir.), Nueva Historia Argentina, Tomo 6: "Democracia, conflicto social y renovación de ideas (1916-1930)", Sudamericana, Buenos Aires, 2000, p. 266.

65. Para datos comparativos (número de escuelas, analfabetos, inversiones, etc.) entre los territorios y entre éstos y las provincias, véase, Biblioteca Nacional (en adelante, BN), Gadano, J. E., Territorios Nacionales, estudio político-económico, Avelardo, Buenos Aires, 1945.

66. BCN, Proyecto de Código Rural para los Territorios Nacionales de la República Argentina presentado al PE de la Nación, Imprenta Las Ciencias, Buenos Aires, 1919, p. 29.

67. BCN, Proyecto de Código Rural para los Territorios Nacionales de la República Argentina presentado al PE de la Nación, Imprenta Las Ciencias, Buenos Aires, 1919, p. 142.

68. Similar pedido de reforma del Código Rural realizó Pablo Taroni, jefe de policía del Territorio Nacional de Formosa, respecto de las incumbencias de la policía en cuanto a la portación de armas y el cuatrerismo. BN, Revista de Policía (en adelante, RP), n564, 16 de diciembre de 1921, p. 585-587. En 1934, el gobernador chaqueño solicitaba al Poder Ejecutivo "la adopción de medidas 
destinadas a restringir el abuso que importa la portación de armas que autoriza el Código Rural sancionado en 1894, y que ya no responde a las necesidades de los mismos". Citado en Mari, O., "Milicias, delitos y control estatal", Op. cit.

69. BN, RP, N 566, 16 de enero de 1922, p. 47 y 48.

70. AHPLP, Orden del Día (en adelante, OD) n¹389, 19 de abril de 1922, libro (en adelante, L) 37.

71. AHPLP, OD N 1389, 19 de abril de 1922, L 37.

72. AHPLP, OD N ${ }^{\circ} 1389,19$ de abril de 1922, L 37.

73. BN, RN, N 566,16 de enero de 1922, p. 47 y 48.

74. AHPLP, LA, 7 de marzo de 1921 y 18 de agosto de 1923.

75. AHPLP, LA, 11 de marzo de 1921.

76. Un estudio inglés plantea que el aumento de los homicidios, del crimen y de la violencia no es proporcional al aumento del número de armas en la población. Sostiene que, en ciertos lapsos de la historia inglesa, el incremento de la violencia ocurrió cuando el uso de las armas estaba restringido. Véase: Malcolm, Joyce Lee, Guns and Violence. The English Experience, Harvard University Press, Cambridge, 2000.

77. AHPLP, LA, 19 de abril de 1918.

78. Argeri, M. E., De guerreros a delincuentes, Op. Cit., pp. 148-149.

79. Carrizo, G. \& Baeza, B., "El mundo del delito en la Patagonia Central”, Op. Cit.

80. AHPLP, LA, 9 y 13 de abril, 16 de diciembre de 1921, 20 de febrero de 1923.

81. AHPLP, LA, 27 de abril y 26 de febrero de 1923, 18 de agosto de 1925. En esa misma línea, ver los casos analizados sobre la policía estadual de Porto Alegre, la policía porteña, la chilena y la mexicana de inicios del siglo XX, respectivamente: Mauch, Claudia, "Masculinidad y violencia en la construcción de la autoridad policial en el inicio del siglo XX en el sur de Brasil", en: Bohoslavsky, Ernesto; Caimari, Lila \& Schettini, Cristiana (Comp.), La policía en perspectiva histórica: Argentina y Brasil desde el siglo XIX a la actualidad, Ediciones del Autor, Buenos Aires, 2009; Barry, Viviana, Orden en Buenos Aires. Policías y modernización policial, 1890-1910, Tesis de Maestría en Historia, Universidad Nacional de San Martín, Buenos Aires, Argentina, 2009; Cárdenas, Vania, "Tras los pasos del ordenamiento policial: oscilaciones en torno a la violencia. Valparaíso 1896-1920", Revista Historia y Justicia, n², Santiago de Chile, 2014, pp. 1-28; Pulido Esteva, D., "Profesional y discrecional", Op. Cit.

82. AHPLP, LA, 16 de febrero de 1923.

83. AHPLP, LA, 14 de junio de 1921.

84. Benjamín, Walter, "Para una crítica de la violencia", Iluminaciones IV, Taurus, Buenos Aires, 1995, pp. 44-45.

85. Bohoslavsky, Ernesto, "La incurable desidia y la ciega imprevisión argentina. Notas sobre el Estado, 1880-1930", en: Vilas, Carlos (Ed.), Estado y política en la Argentina actual, Prometeo, Buenos Aires, 2005, pp. 107-129.

86. Garland, D., Castigo y sociedad moderna, Op. Cit., p. 261.

87. Gelman, J., “Crisis y reconstrucción del orden”, Op. Cit., pp. 9-10.

88. En particular, véase para la campaña bonaerense: Yangilevich, M., Estado y criminalidad, Op. Cit.; Fradkin, R., “Entre la ley y la práctica”, Op. Cit.; Garavaglia, J. C., "Paz, orden y trabajo”, Op. Cit.; Salvatore, R., Wandering Paysanos, Op. cit.

89. La literatura académica sobre el tema -sobre todo los especialistas en historia colonial quienes realizaron los primeros abordajes- ha sostenido que el sistema judicial implementado en América estuvo lejos de ser exclusivamente un instrumento de dominación en manos de los grupos dirigentes. Al respecto, véase Yangilevich, M., Estado y criminalidad, Op. Cit., pp. 23-25.

90. Hartmut, Keil \& Riekenberg, Michael, "Violence in the United States and Latin America in the Nineteenth Century: A Comparative Approach”, Iberoamericana, nº 4, Berlín, 2001, p. 58.

91. L'Heulliet, Hélène, Baja política, alta policía. Un enfoque histórico y filosófico de la policía, Prometeo, Buenos Aires, 2010. 


\section{RESÚMENES}

Este artículo aborda el medio siglo transcurrido entre 1884 y 1930, para examinar la articulación entre la figura policial, en tanto representante de un Estado regulador de la violencia, y el uso efectivo de la violencia en las prácticas sociales. Los habitantes del Territorio Nacional de La Pampa temían que el uso de las armas trajera a la ciudad el tipo de brutalidad que se asociaba con la vida rural. Desde los años 1920s, diferentes sectores con mayor incidencia política, económica y social se esforzarán por administrar y hacer efectivo el monopolio de la violencia.

Cet article traite du demi-siècle qui s'est écoulé entre 1884 et 1930, afin d'examiner l'articulation entre la figure policière, en tant que représentante d'un État régulateur de la violence, et l'utilisation efficace de la violence dans les pratiques sociales. Les habitants du territoire national de La Pampa craignaient que l'utilisation des armes n'apporte à la ville le genre de brutalité associée à la vie rurale. Depuis les années 1920, différents secteurs ayant une plus grande influence politique, économique et sociale s'efforcent d'administrer et de faire respecter le monopole de la violence.

This article examines the half century between 1884 and 1930, to analyses the articulation between the police figure as representative of a state regulating violence, and the effective use of violence in social practices. The inhabitants of the National Territory of La Pampa feared that the use of weapons would bring to the city the kind of brutality that was associated with rural life. Since the 1920s, different sectors with greater political, economic and social impact will strive to manage violence and to realize the monopoly of violence.

\section{ÍNDICE}

Palabras claves: espacio rural, policía, violencia, Territorio Nacional de La Pampa, siglos XIX-XX Keywords: Rural space, XIX-XX centuries, police, violence, National Territory of La Pampa Mots-clés: espace rural, police, violence, territoire national de La Pampa, XIX-XX siècles

\section{AUTOR}

\section{MELISA FERNÁNDEZ MARRÓN}

Doctora en Historia, Universidad de San Andrés. Docente investigadora, Universidad Nacional de Río Negro, Instituto de Investigación en Políticas Públicas y Gobierno. Correo electrónico: mfmarron[at]unrn.edu.ar 